\title{
1 Iron-based shape memory alloy strips for strengthening RC members: 2 Material behavior and characterization
}

3 Moslem Shahverdi ${ }^{*}$, Julien Michels ${ }^{1,2}$, Christoph Czaderski ${ }^{1}$, Masoud Motavalli ${ }^{1}$

$4 \quad{ }^{1}$ Swiss Federal Laboratories for Materials Science and Technology (Empa), Dübendorf, Switzerland

$5 \quad{ }^{2}$ re-fer AG, Brunnen, Switzerland

6 *Corresponding author:

$7 \quad$ Tel: +41 5876543 82; Email: moslem.shahverdi@empa.ch

9 Abstract: Shape memory alloys (SMAs), in the form of bars and strips, can be used as pre10 stressing elements in new reinforced concrete (RC) members or for strengthening existing RC 11 structures, owing to their special characteristic known as the shape memory effect (SME). When the SME comes into play, the material returns to its initial shape upon heating after having been deformed at ambient temperatures. If a return to the initial shape is prevented by mechanical fixation, stress develops in the SMA. A cost-effective iron-based SMA (Fe-SMA) has been developed for application in civil engineering structures. The composition of the developed alloy is $\mathrm{Fe}-17 \mathrm{Mn}-5 \mathrm{Si}-10 \mathrm{Cr}-4 \mathrm{Ni}-1(\mathrm{~V}, \mathrm{C})$ (mass\%). This Fe-SMA exhibits high tensile strength, excellent shape recovery stress (prestress force), and high elastic stiffness. Moreover, its material cost is low and it is easier to manufacture than nickel-titanium (NiTi) alloys. Recently, Fe-SMA strip production has been started at an industrial scale. In this study, the experimentally determined properties of such industrially produced Fe-SMA strips are presented, and their recovery stress and recovery strain have been measured. The effects of prestraining and maximum heating temperature on the obtained recovery stress have been studied. These Fe-SMA strips can be used as external end-fixed reinforcements to strengthen RC structures.

Keywords: Shape memory alloy (SMA), iron-based SMA (Fe-SMA), recovery stress, shape memory effect (SME), prestress, material characterization

This document is the accepted manuscript version of the following article: Shahverdi, M., Michels, J., Czaderski, C., \& Motava11i, M. (2018). Iron-based shape memory alloy strips for strengthening RC members: Material behavior and characterization. Construction and Building Materials, 173, 586-599. http://doi .org/10.1016/j. conbui 1dmat.2018.04.057 

austenite start temperature

$b \quad$ width of the specimen

$\Delta \sigma_{\text {relx }} \quad$ reduction in stress during the relaxation experiment

$E_{1} \quad$ elastic modulus determined in the stress range of 20-200 MPa in tensile mode

$E_{2} \quad$ elastic modulus determined in the stress range of 20-80 MPa after activation

$E_{\text {act-eq }} \quad$ equivalent elastic modulus of activation

$\varepsilon_{\text {rec }} \quad$ recovery strain; strain in the SMA which recovers during activation

$\varepsilon_{\mathrm{pl}} \quad$ plastic strain

$\varepsilon_{\text {Pel }} \quad$ pseudoelastic strain; strain in the SMA which recovers nonlinearly by unloading

$\varepsilon_{u} \quad$ ultimate tensile strain; maximum strain reached in axial tensile tests

$\varepsilon_{\mathrm{el}} \quad$ elastic strain

$\varepsilon_{\mathrm{p}} \quad$ prestraining strain

$f_{u} \quad$ ultimate tensile strength; maximum stress reached in axial tensile tests

$\sigma_{\text {max-relx }} \quad$ maximum stress applied to the specimen during the relaxation experiments

$\sigma_{\text {rec }} \quad$ recovery stress; stress developed in the SMA during activation, i.e., the prestress

$P_{\text {ini }} \quad$ preload applied to the specimens before activation

$P_{\text {ser }} \quad$ service load

$R_{\mathrm{p} 0.2} \quad$ offset yield point (proof stress) at $0.2 \%$ plastic strain

$t \quad$ thickness of the specimens, $0.5 \mathrm{~mm}$ or $1.5 \mathrm{~mm}$

$T_{\max } \quad$ maximum temperature applied during activation

$t_{\text {relx }} \quad$ relaxation experiment time

Activation triggering of phase transformation in the SMA so that a prestress is developed

Fe-SMA iron-based shape memory alloy

NiTi nickel-titanium

NiTi-SMA nickel titanium SMA

NSM near surface mounted

RC reinforced concrete

RT room temperature

SMA shape memory alloy

SME shape memory effect 
30 New and innovative methods to strengthen existing civil structures such as bridges and buildings and to build new structures are necessary in the construction industry. A new type of advanced materials entering the construction market are shape memory alloys (SMAs). SMAs have two main characteristic properties: "superelasticity" and "shape memory effect" (SME). SMAs with superelasticity can return to their initial shape after loading and unloading; however, SMAs with SME return to their initial shape upon heating. Such materials, for e.g. NiTi alloys, have been around for a long time, but were not considered suitable for the construction industry due to their expensive nature $[1,2]$.

The most commonly known SMAs are NiTi alloys. These materials are used in the automotive, aerospace, robotic, and biomedical domains [3]. SMAs can be used as self-centering elements, dampers, sensors, or actuators. Furthermore, there are a multitude of reports on SMAs and their applications in civil engineering [4-9].

In civil engineering applications, SMAs can be exploited for their superelasticity or SME properties for example NiTiNb alloys [10-12]. Some demonstration projects do exist in this context [1, 13-18]. However, the application of SMAs in this domain is still in the research stage [19]. The vast majority of previous studies concentrated on the superelasticity properties of SMA. Although the expensive NiTi-based alloys are the most widely used SMAs [1], low-cost copperbased shape memory alloys (Cu-SMAs) and Fe-SMAs are gaining ground [2, 20-22]. Cu-SMAs have superelastic properties with a low elastic modulus and low cycle fatigue resistance [22]. However, in the case of Fe-SMAs, in addition to their lower cost than the NiTi-based alloys, they have a higher elastic modulus and can be activated at relatively lower temperatures [23]. This makes them very promising for strengthening existing civil structures and for prestressing new civil structures as well.

The Fe-SMA material was discovered by Sato et al. [24] in 1982. Fundamental research on the transformation behavior, microstructural and crystallographic characteristics, and mechanical properties of Fe-Mn-Si-based alloys were performed at the National Institute for Materials Science (NIMS), Japan [25-27]. Watanabe et al. [28] worked on the reinforcement of an $80 \mathrm{~mm}$ long plaster prism specimen with a $1 \mathrm{~mm}$ diameter prestressed wire made of $\mathrm{Fe}-27 \mathrm{Mn}-6 \mathrm{Si}-5 \mathrm{Cr}-$ $0.05 \mathrm{C}$. The wires were subjected to a pretensile strain $(1 \%, 2 \%$, and $3 \%)$ at room temperature (RT) and were embedded into a plaster matrix. In 2001, Soroushian et al. reported the strengthening of a bridge in Michigan, USA through external post-tensioning with Fe-Mn-Si-Cr SMA rebars [29]. 
At Empa, the Swiss Federal Laboratories for Materials Science and Technology, extensive studies on SMAs for civil engineering applications have been carried out over the past few years [23, 30-33]. In 2003, a concrete beam was longitudinally reinforced with SMA wires [34]. In 2003/2004, NiTi-SMA wires were embedded in mortar to demonstrate the feasibility of prestressed short fiber reinforced concrete [35]. The total fiber content was $1.2 \%$ by volume. A compression stress of approximately $7 \mathrm{MPa}$ was determined in the concrete prisms. A new FeSMA for civil engineering applications was developed by Dong et al. [30]. The composition of the developed alloy was $\mathrm{Fe}-17 \mathrm{Mn}-5 \mathrm{Si}-10 \mathrm{Cr}-4 \mathrm{Ni}-1(\mathrm{~V}, \mathrm{C})$ (mass\%). For civil engineering applications, Fe-SMAs represent a promising technology in a number of areas because of their properties and lower cost than NiTi. Fe-SMAs are less expensive compared to (NiTi) alloys because their row material cost is low and they are easier to be manufactured than nickel-titanium (NiTi) alloys. The newly developed Fe-SMA can be activated at temperatures between $100{ }^{\circ} \mathrm{C}$ and $250{ }^{\circ} \mathrm{C}$ by resistive heating over a short period time (about one minute). Furthermore, it can be produced on an industrial scale at atmospheric conditions without expensive, high-vacuum processing facilities. For different applications, it can be manufactured in appropriate shapes such as ribbed bars or strips by hot and/or cold forming.

In 2012, a feasibility study began on the use of Fe-SMAs for strengthening reinforced concrete structures [36, 37]. The idea was to use Fe-SMA strips as near surface mounted (NSM) reinforcements. In this project, several RC beams were strengthened with the NSM technique using prototype Fe-SMA strips [37]. The recovery stress (prestress force) after prestraining to $2.0 \%$ or $4.0 \%$ and heating to $160{ }^{\circ} \mathrm{C}$ was in the range of $250-300 \mathrm{MPa}$ [36]. In another project, prototype ribbed Fe-SMA bars were produced at the laboratory level to strengthen RC structures in combination with shotcrete [38]. Both products were produced at lab scale in collaboration with the Montanuniversität, Leoben (Austria) and the Bergakademie TU, Freiberg (Germany).

The application of Fe-SMA strips for prestressing concrete members consists of three main actions, as schematically shown in Figure 1. (1) Prestraining: The Fe-SMA strips are pre-strained to a specific strain level and later fully released. (2) Activation: The Fe-SMA strips are activated (heating and cooling back to RT while they are fixed externally to the concrete structure. (3) Service loading: When the concrete structure is loaded, the Fe-SMA strips will carry load as shown in the left panel in Figure 1.

The heating and cooling of an Fe-SMA strip while it is constrained will produce a recovery stress, as shown in Figure 1 (red line noted as 2). The shape memory effect (i.e., generating the recovery stress) of the iron-based SMAs is due to the stress-induced martensite transformation 
close packed, hcp) at RT and the reverse transformation ( $\varepsilon$ - to y-phase) when heated beyond the transformation temperature. At the beginning of the heating cycle, the SMA will thermally expand. At austenite start temperature, As, the transformation from hcp to fcc starts and compressive stresses are created in the concrete element due to the development of tensile stresses in the SMA. During cooling, further compressive stresses build up in the concrete element due to thermal contraction of the SMA (Figure 1, right panel). Phase change temperatures for the studied Fe-SMA have been reported in [32] as follow: $\mathrm{M}_{\mathrm{f}}=-64{ }^{\circ} \mathrm{C}, \mathrm{M}_{\mathrm{s}}=-60{ }^{\circ} \mathrm{C}, \mathrm{A}_{\mathrm{s}}=103{ }^{\circ} \mathrm{C}$, and $\mathrm{A}_{\mathrm{f}}=163{ }^{\circ} \mathrm{C}$.

From an application point of view, it is important to have a clear understanding of the thermomechanical behavior of SMAs in order to fully exploit their potential. Transformation phase diagrams are particularly important when using SMA strips since their thermomechanical behavior is determined by the phase transformations between $\varepsilon$ and $\gamma$ phases. However, due to differences in the crystal structure, Fe-SMAs exhibit different thermomechanical properties as compared to the classic NiTi alloys [31]. The amount of recovery strain in Fe-SMAs strongly depends on the temperature at which the martensitic transformation takes place $[23,30]$. The physical background for such a behavior is the reversible transformation occurring between the atomic crystal structures, i.e., austenite (fcc) and martensite (hcp) [2, 25, 31].

There are few studies available on the basic phase transformation behavior of Fe-SMAs. Maruyama and Kubo [39] and Baraj et al. [40] investigated the critical stress for martensitic transformation in Fe-SMAs. Lee et al. [31] studied the phase transformation behavior and transformation conditions of the $\mathrm{Fe}-17 \mathrm{Mn}-5 \mathrm{Si}-10 \mathrm{Cr}-4 \mathrm{Ni}-1(\mathrm{~V}, \mathrm{C})(\mathrm{mass} \%)$ alloy. It was shown that the critical stress for the formation of $\varepsilon$-martensite in the alloy initially increases and then decreases with increasing temperature. It, therefore, indicated two distinct deformation states caused by martensitic transformation and irrecoverable slip.

In this study, the material properties of the Fe-SMA strips produced at an industrial scale are determined experimentally. The aim of the investigation is to provide a detailed material characterization of the iron-based SMAs. Such investigations are useful to propose (or modify and extend [31]) a phase diagram, which is helpful in understanding the thermo-mechanical characteristics and in developing constitutive models. In addition, these results can be used directly for the real-time application of the strips , e.g., as proposed by Michels et al. as an external end-anchored and unbonded prestressing system for structural retrofitting [41, 42]. 


\section{Production of the Fe-SMA strips}

128 As mentioned earlier, an iron-based shape memory alloy with a composition of $\mathrm{Fe}-17 \mathrm{Mn}-5 \mathrm{Si}-$ $12910 \mathrm{Cr}-4 \mathrm{Ni}-1(\mathrm{~V}, \mathrm{C})($ mass\%) was developed at Empa [30]. In the past, production was limited to

130 lab scale alone in which around $100 \mathrm{~kg}$ could be produced. However, re-fer AG in collaboration 131 with a stainless steel producer recently manufactured Fe-SMA strips at the industrial level. 132 Roughly, the following steps were performed. Initially, a batch of 8 tons of the alloy with the 133 same composition as described in [30] was cast. Subsequently, billets with dimensions of ap134 proximately $130 \times 130 \times 4000 \mathrm{~mm}^{3}$ were produced. In the next step, the billets were heated in 135 an oven to a temperature higher than $1100{ }^{\circ} \mathrm{C}$ and the cross-sections of the blocks were reduced 136 to approximately $3 \mathrm{~mm} \times 150 \mathrm{~mm}$ by hot-rolling. After this process, strips with final thicknesses 137 of $1.5 \mathrm{~mm}$ and $0.5 \mathrm{~mm}$ with corresponding widths of $100 \mathrm{~mm}$ and $50 \mathrm{~mm}$ were produced by a 138 few cycles of cold rolling. The final coils of the strip material are presented in Figure 2.

\section{3. Experiments}

\section{$140 \quad 3.1$ Specimen geometry and cutting}

141 To characterize the thermo-mechanical properties of the studied Fe-SMA strips, tensile speci142 mens with a length of $250 \mathrm{~mm}$ and width of $15 \mathrm{~mm}$ were cut out from the as received Fe-SMA 143 strips, see Figure 3. In the case of the 1.5-mm-thick strips, two different cut-outs were procured, 144 one from the middle (denoted as M) and the other from the border (denoted as R). In addition, 145 these samples were used for activation in a climate-controlled chamber.

146 In another series of experiments, long specimens with a length of $2200 \mathrm{~mm}$ and width of $10 \mathrm{~mm}$ 147 were cut out from the middle of the 100 -mm-wide and 1.5 -mm-thick strips. These specimens 148 were used for activation "in air" and relaxation experiments.

\section{$149 \quad$ 3.2. Failure tensile experiments (testing set-up No. 1)}

150 Tensile experiments were performed at RT at a displacement rate of $3 \mathrm{~mm} / \mathrm{min}$ up to failure on 151 a $200 \mathrm{kN}$ Zwick tensile testing machine [43]. An extensometer of the Zwick Makro type was 152 used for strain measurement, as shown in Figure 4.

\subsection{Prestraining, activation, and recovery strain of short Fe-SMA strips}

\subsubsection{Prestraining of short Fe-SMA strips (testing set-up No. 2)} $\mathrm{kN}$ Zwick machine. The experiments were performed at a displacement (strain) rate of 1 
$\mathrm{mm} / \mathrm{min}$. The developed strain was measured using an extensometer with a gauge length of 100 $\mathrm{mm}$. After the desired prestrain was reached, the load was completely released (machine displacement controlled at a rate of $0.5 \mathrm{~mm} / \mathrm{min}$ ).

\subsubsection{Activation of short Fe-SMA strips (testing set-up No. 2)}

For the heating experiments on short specimens, a climate-controlled chamber was added to the $20 \mathrm{kN}$ Zwick machine. Figure 5 shows the climate-controlled chamber, the clamps, the Fe-SMA strip, and the extensometer. A special clip-on extensometer with a gauge length of $100 \mathrm{~mm}$ was used for the heating experiments. The temperature-induced expansion of the extensometer was continuously compensated during the experiments by a control in the testing machine.

At the start of the heating experiments, the Fe-SMA test specimens were preloaded to avoid compression due to thermal expansion during heating. Then, while holding the strain constant (i.e., a strain change of zero), the temperature was increased from $23{ }^{\circ} \mathrm{C}$ up to a target temperature, $T_{\max }$, at a rate of $2{ }^{\circ} \mathrm{C} / \mathrm{min}$. After holding the test specimen for $1 \mathrm{~h}$ at $T_{\max }$, the temperature was decreased again at approximately $2{ }^{\circ} \mathrm{C} / \mathrm{min}$ down to $23{ }^{\circ} \mathrm{C}$. The maximum axial stresses in the Fe-SMA strips after a further waiting time of $1 \mathrm{~h}$ at $23{ }^{\circ} \mathrm{C}$ were considered to be the recovery stresses, $\sigma_{\text {rec }}$.

The effects of the following parameters on the recovery stress were studied.

$$
\begin{array}{ll}
\text { - } & \text { Strip thickness, } t \\
\text { - } & \text { Cutting position } \\
\text { - } & \text { Machine preload, } P_{i n i} \\
\text { - } & \text { Prestraining, } \varepsilon_{p} \text {, and } \\
& \text { Maximum heating temperature, } T_{\max }
\end{array}
$$

The behavior of the activated Fe-SMA strips subjected to axial tensile loading after activation or "service loading" was studied in another series of experiments. In such experiments, after the activation process, the strips were held in the machine and an additional tensile load, 3-4 times greater than the service load, was applied. The strains and stresses were then recorded continuously.

\subsubsection{Recovery strain, $\varepsilon_{\text {rec, }}$ in short Fe-SMA strips (testing set-up No. 2)}

After prestraining the Fe-SMA strips, the residual prestrain is partially recovered when the sample is heated. This strain is called the "recovery strain" due to heating. It is important to know 
187 the amount of recovery strain that can be obtained when the Fe-SMA strip is free to move back

188 to its initial shape. To measure the recovery strain, experiments on Fe-SMA strips with different

189 prestrains were conducted on the Zwick testing machine equipped with a climate-controlled

190 chamber. For these tests, the Fe-SMA strips were fixed at both ends and subjected to a very

191 small preload of about $1 \mathrm{MPa}$. Keeping this preload constant, heating and cooling cycles were

192 performed, similar to a normal activation experiment inside the climate-controlled chamber, as

193 described in Section 3.3.2 for stress recovery. During the heating and cooling processes, the axi-

194 al strains in the strip were measured with a clip-on extensometer and recorded continuously.

195 The final strain measured at the end of the experiment was reported as the "recovery strain."

196 3.4. Prestraining, activation, and stress-relaxation of long Fe-SMA strips

197 3.4.1. Prestraining of long Fe-SMA strips (testing set-up No. 3)

198 Prestraining of the long Fe-SMA strips was done on a testing set-up shown in Figure 6. The 199 strips were prestrained to a $2.0 \%$ elongation at RT by a manually operated oil hydraulic jack and 200 then released to a stress-free state when the elastic strain was recovered. The Fe-SMA strips 201 were clamped at the ends with mechanical steel clamps, which were then supported vertically. 202 The resultant elongation was measured by a draw-wire displacement sensor, as shown in Figure 2036.

\subsubsection{Activation of long Fe-SMA strips (testing set-up No. 4)}

Long Fe-SMA strips were activated in a testing set-up shown in Figure 7. The Fe-SMA strips were mechanically clamped at both ends between two steel columns; the length between the clamps was approximately $2 \mathrm{~m}$. A load cell with a capacity of $100 \mathrm{kN}$ was placed on one side in between the mechanical clamp and the steel column. Wooden plates were used to electrically isolate the mechanical clamp from the load cell and steel column and a Teflon tube was used to isolate the load cell electrically from the Fe-SMA strip. Teflon tubes were used to secure the isolation between the strip and steel columns.

212 The Fe-SMA strips were activated by resistive heating with a custom-made electric power sup-

213 ply. Special clamps (Figure 7, right panel) with air pressure were used to secure the contacts be214 tween the cables from the power supply and the Fe-SMA strips. A relatively high current densi215 ty of approximately $8.3 \mathrm{~A} / \mathrm{mm}^{2}$ was applied. The temperature on the strip was measured by 216 means of Type $\mathrm{K}$ thermocouples. In some experimental runs, an infrared camera was employed 217 in addition to the thermocouples to record the temperature on the strip and its distribution over 218 the length. When the temperature measured by the thermocouples reached the target tempera- 
219 ture, the power supply was manually switched off. Because the specimens were subjected to air

220 flow, such activation is named "activation in air."

\subsubsection{Stress relaxation of long Fe-SMA strips (testing set-up No. 4)}

222 Using testing set-up No. 4, stress relaxation behavior of the Fe-SMA strips was studied. The setup was equipped with a wireless long-term data acquisition system to record the load and temperature continuously. The measurements are accessible online at all times [44]. Three different stress relaxation experiments were performed.

i) Relaxation behavior of the mechanically prestressed as received Fe-SMA strip: In these

\section{Results and discussion}

\subsection{Stress-strain behavior}

241 The stress-strain behaviors of the examined strips under axial tensile loading are depicted in 242 Figure 8 and Figure 9 for strip thicknesses of $0.5 \mathrm{~mm}$ and $1.5 \mathrm{~mm}$, respectively. The Fe-SMA 243 strips had an ultimate tensile strength, $f_{S M A, u}$, of about $1000 \mathrm{MPa}$ with a corresponding minimum 244 strain of $47 \%$ and $37 \%$ at thicknesses of $0.5 \mathrm{~mm}$ and $1.5 \mathrm{~mm}$, respectively (Table 1). The strains 245 at failure, $\varepsilon_{S M A, u}$, were more than $48 \%$ and $42 \%$, higher than the strains at maximum tensile 246 strength. Both types of strips showed a very ductile behavior. The elastic modulus determined 247 from the stress-strain results was approximately $160 \mathrm{GPa}$. The elastic modulus was determined by best fit trend line fitted within stress range of 20 to $200 \mathrm{MPa}$. 
249 Because the yield point could not be easily defined from the shape of the stress-strain curve, an

250 offset yield point is arbitrarily defined. The value for the offset yield point (proof stress), $R_{\mathrm{p} 0.2}$, is 251 set at $0.2 \%$ plastic strain, as shown in Table 1 .

252 Prestraining of the 1.5-mm-thick short Fe-SMA strips to different prestraining levels is depicted 253 in Figure 10. Figure 11 shows the prestraining of the 1.5 -mm-thick long Fe-SMA strips to a pre254 straining level of $2.0 \%$. The fluctuations in the curves are due to the manually operated hydrau255 lic jack. The overall stress-strain behaviors, however, are similar to the reference tensile exper256 iment performed in the machine testing set-up No. 1, as shown in Figure 10 and Figure 11.

257 The nonlinear deformation behavior during loading is due to either a phase transformation from 258 austenite to martensite or a plastic deformation or a combination of both. When unloading, the 259 load also deviates from the linear elastic behavior. The deviation from linear elastic discharge is 260 called a pseudoelastic strain (Figure 12). In Figure 12, the elastic strain $\left(\varepsilon_{e l}=0.42 \%\right.$ ), pseudoe261 lastic strain $\left(\varepsilon_{P e l}=0.33 \%\right)$, and "recovery strain and plastic strain" (1.25\%) are shown for a strip 262 with $\varepsilon_{p}=2.0 \%$ prestraining. The remaining permanent deformation of $1.25 \%$ can be partially re263 covered by activation, see Section 4.2.

\subsection{Recovery strain}

265 The amount of recovery strain depends on the heating temperature and on the amount of mar266 tensite present in the alloy. The amount of martensite generated during prestraining depends on 267 the deformation level and deformation temperature. Figure 13 shows recovery strain measure268 ment of representative 1.5 -mm-thick specimens prestrained to $0.5 \%, 1.0 \%, 2.0 \%, 4.0 \%$, and $2696.0 \%$. The final recovery strains after heating to $160{ }^{\circ} \mathrm{C}$ and cooling to $23{ }^{\circ} \mathrm{C}$ were in the range 270 of $0.15-0.4 \%$, as detailed in Table 2. In general if there is a gap during the application, part of 271 the recovery strain is used to compensate the gap, it is, therefore, expected to receive less effi272 cient recovery stress.

273 Figure 14 shows the effect of prestraining on the obtained recovery strain. It increases up to $2742.0 \%$ initial prestraining; however, more prestraining does not lead to a clear higher recovery 275 strain. It can therefore be concluded that an initial prestraining of $2.0 \%$ is enough to achieve the 276 maximum recovery strain.

\subsection{Recovery stress}

278 When the recovery strain is hindered due to a controlled constant strip strain, "recovery stress" 279 is generated inside the sample. In this section, recovery stresses obtained from the constrained 
280 heating and cooling experiments on different specimens are described (Table 3). The effects of

281 different parameters on the final recovery stress are discussed hereafter.

\section{$282 \quad$ 4.3.1. Effect of strip thickness on the recovery stress}

283 Figure 15 compares the recovery stress versus temperature curves of representative specimens 284 for 0.5 -mm-thick and 1.5 -mm-thick strips prestrained to $4.0 \%$ and heated to a maximum tem285 perature of $160^{\circ} \mathrm{C}$. Although the two curves showed some differences and were not identical, 286 they were similar in overall. The obtained recovery stresses are approximately the same and the 287 difference lies is in the range of scattering. Therefore, it could be concluded that there is no dif288 ference between the 0.5 -mm-thick and 1.5-mm-thick Fe-SMA strips in terms of the obtained re289 covery stress.

\section{$290 \quad$ 4.3.2. Effect of cutting position on the recovery stress}

291 Figure 16 and Figure 17 compare the recovery stress versus temperature curves of the speci292 mens cut out from middle and the border of a 1.5-mm-thick Fe-SMA strip (Figure 3). The spec293 imens were subjected to $2.0 \%$ and $4.0 \%$ prestraining before activation and heated to a maximum 294 temperature of $160^{\circ} \mathrm{C}$. The recovery stresses obtained by cooling down the specimens to RT 295 were approximately the same for both cutouts. Therefore, it could be concluded that there is no 296 effect of the cutting position on the obtained recovery stress.

\subsubsection{Effect of machine preload on the recovery stress}

298 As mentioned in Section 3.3.2, at the start of the heating experiments, the Fe-SMA test speci299 mens were preloaded to avoid compression in the test specimens due to thermal expansion dur300 ing heating. Figure 18 compares the recovery stresses versus temperature curves of the repre301 sentative specimens subjected to different machine preloads. A higher preload leads to a higher 302 temperature point for the start of the phase transformation. In Figure 18, the temperature point 303 for a preload of $100 \mathrm{MPa}$ is higher than $50^{\circ} \mathrm{C}$; however, for the other preloads, it is below 50 $304{ }^{\circ} \mathrm{C}$. The obtained stress at the end of the heating phase and the "recovery stress," after heating 305 and cooling, are not significantly affected by the machine preload.

\section{$306 \quad$ 4.3.4. Effect of prestraining on the recovery stress}

307 Figure 19 shows the effect of strip prestraining on the recovery stress versus temperature curves 308 of the 1.5 -mm-thick Fe-SMA strips subjected to a maximum temperature of $160{ }^{\circ} \mathrm{C}$. It can be 309 observed that the obtained recovery stress depends on the amount of prestraining before the ac- 
310 tivation as shown in Figure 20, in which the obtained recovery stresses at different prestrain lev-

311 els are depicted. The increasing trend of the recovery stress by increasing the prestraining

312 reaches a plateau at $2 \%$ prestraining. According to the obtained results, a prestraining of $2.0 \%$ or

$3134.0 \%$ is the optimum level to achieve the highest recovery stress when heating to $160{ }^{\circ} \mathrm{C}$. De-

314 termination of the optimal prestraining for higher temperature can be obtained by the same pro-

315 cedure. A different optimal value for higher temperature is expected, see Section 4.3.5.

316 The results described in this section are in agreement with the results obtained in Section 4.2.

317 The generated recovery stress is directly linked to the recovery strain. An equivalent elastic

318 modulus of $95 \mathrm{GPa}$, averaged from the different prestraining levels, could be used to determine

319 the recovery stress according to the obtained recovery strain.

\section{$320 \quad$ 4.3.5. Effect of the maximum heating temperature on the recovery stress}

321 Figure 21 compares the recovery stress versus temperature curves of the representative speci322 mens subjected to three different maximum heating temperatures, $120{ }^{\circ} \mathrm{C}, 160{ }^{\circ} \mathrm{C}$, and $195{ }^{\circ} \mathrm{C}$.

323 The $1.5-\mathrm{mm}$-thick strips used in this study were prestrained to $2.0 \%$ before activation. The re-

324 covery stresses were higher in the strips subjected to a higher maximum temperature, as shown

325 in Figure 21 and Table 3. As the austenite finished temperature, $\mathrm{A}_{\mathrm{f}}$, of the studied ally is about

$326163^{\circ} \mathrm{C}$ [32], recovery stresses obtained by maximum temperature of below $\mathrm{A}_{\mathrm{f}}$ are due to partial

327 activation. As Due to the limitations of the experimental set-up No. 2, temperatures above 200

$328{ }^{\circ} \mathrm{C}$ were not possible.

329 Activation at higher temperatures was conducted "in the air" by resistive heating, according to 330 testing set-up No. 4. Figure 22 exhibits an image captured by the infrared video camera from the 331 left side of the Fe-SMA strip during activation in the air (see Figure 7). As can be seen in Figure 33222 the temperature in the Fe-SMA strip is about $180^{\circ} \mathrm{C}$. Figure 23 shows the stress that was de333 veloped in the strip at the corresponding maximum temperature recorded by the infrared camera 334 on the strip. A recovery stress of about $445 \mathrm{MPa}$ was determined at the maximum activation 335 temperature of $380{ }^{\circ} \mathrm{C}$. Table 4 summarizes the results of all the activation experiments per336 formed in air. Basically, higher temperature induces more phase transformation in the alloy; it 337 therefore results in higher recovery stress. However, such increase is not always the case, and 338 there is a maximum portion of phase transformation that can be expected by increasing the max339 imum heating temperature.

340 The results obtained from 2\% prestrained strips are depicted in Figure 24. The combination of 341 the results obtained after activation in the climate-controlled chamber and activation in the air 
342 shows the effect of maximum temperature on the obtained recovery stress. The trend in the ob-

343 tained results is also depicted in Figure 24. It is expected that the increasing trend reaches a

344 maximum with no further increase in the stress even though the temperature is increased; prob-

345 ably, a decrease will occur at higher temperatures.

346 It is worth mentioning that the heating phase during resistive heating was less than one minute 347 whereas the cooling phase took about ten minutes. In comparison with the activation experi348 ments carried out in the climate-controlled chamber over several hours, such an activation pro349 cedure is very fast. The activation experiments in air resulted in recovery stresses similar to 350 those obtained from experiments performed in the climate-controlled chamber. It was therefore 351 concluded that the heating and cooling rates do not have a significant influence on the obtained 352 recovery stress.

\section{4.4. Relaxation of the Fe-SMA strips}

354 Figure 25 shows an example of the stress relaxation behavior of the studied Fe-SMA strips on a 355 logarithmic scale. In this example, the changes in the tensile stress over time after the activation 356 of the strip are shown. The experiment was performed in laboratory conditions at ambient room 357 temperature, the variation in which was about $\pm 2{ }^{\circ} \mathrm{C}$; this causes a slight fluctuation in the stress 358 level recorded over time. The stress relaxation (ratio of actual stress to maximum stress) in per359 centage terms is depicted in Figure 25. The maximum stress relaxation values after more than $3601000 \mathrm{~h}$ for differently examined strips are presented in Table 5. The results indicate that the re361 laxation behavior of the studied Fe-SMA strips was similar under the three different prestressing 362 scenarios.

\section{$363 \quad$ 4.5. Loading after activation}

364 An important aspect of the application of prestressed Fe-SMA strips is their behavior under ad365 ditional load after activation. Such a load can be considered as the service load in buildings and 366 construction structures. A thorough knowledge of this behavior is needed for designing SMAs 367 for real-time applications. Figure 26 shows the stress-strain behavior of a representative 1.5368 mm-thick strip prestrained to $2.0 \%$ and activated at a maximum temperature of $160{ }^{\circ} \mathrm{C}$. The 369 stress-strain curve due to additional loading reaches the initial curve; however, the tensile stiff370 ness is different at the beginning. For design purposes, an elastic modulus (as shown in Figure 371 26) should be used. For such a high additional loading the effect of pre-straining disappears, 372 however, this will not be the case in reality. In the current investigation, such extremely high 373 additional loading has been applied to determine the stress-strain behavior of the studied SMA 
after activation. The reason for such loss could be correlated by the unrecoverable plastic deformation in the alloy. In fact, the reserved-recovery-strain is employed to compensate the high plastic strain introduced into alloy by high level of additional loading.

The additional stress-strain behavior after activation depends on the recovery stress obtained from the activation experiments. In Figure 27, the stress-strain curves of representative specimens subjected to maximum temperatures of $120^{\circ} \mathrm{C}, 160^{\circ} \mathrm{C}$, and $195^{\circ} \mathrm{C}$ are depicted. The initial slopes in those cases with lower recovery stresses are higher than those with higher recovery stresses. This difference is important and should be considered during design when Fe-SMA strips are used for real-time structural applications [41].

\section{Conclusions}

In this study, material characterization of Fe-SMA strips produced at an industrial level for the strengthening of RC members was performed. The characterizations were carried out at engineering standards to match the intended purpose of application in civil engineering structures. The following conclusions were drawn from our investigation.

- The Fe-SMA strips showed excellent mechanical properties. Their behavior in unidirectional tension is very ductile till their failure. An ultimate tensile strength of about 1000 $\mathrm{MPa}$ with a corresponding strain at failure of more than $40 \%$ was obtained. Recovery stresses of 300 to $350 \mathrm{MPa}$ were measured after heating the Fe-SMA strips to $160{ }^{\circ} \mathrm{C}$.

- The cutting position did not have any significant effect on the obtained recovery stress. In terms of prestress, the material behaves uniformly along the whole width of $100 \mathrm{~mm}$.

- The obtained recovery stresses for both thin $(0.5 \mathrm{~mm})$ and thick $(1.5 \mathrm{~mm})$ strips were identical.

- Prestraining influenced the obtained recovery stress. For the studied Fe-SMA strips, a prestraining of $2.0 \%$ was found to be sufficient in order to obtain the maximum possible recovery stress after heating the Fe-SMA strips to $160{ }^{\circ} \mathrm{C}$.

- Activation at higher temperatures leads to a higher recovery stress. It is expected that the increasing trend reaches a maximum at a heating temperature of about $400{ }^{\circ} \mathrm{C}$. At this temperature, the obtained recovery stress is about $450 \mathrm{MPa}$.

- Recovery strains of about $0.15 \%$ to $0.40 \%$ were measured during the heating/cooling cycle of the 1.5 -mm-thick strip to/from a temperature of $160^{\circ} \mathrm{C}$.

- Loading the Fe-SMA strips after activation showed that their stress-strain curve overlaps the stress-strain curve obtained during tensile studies. However, the tensile stiffness is dif- 
ferent just after activation, and it also depends on the prestress level. These stiffness values should be used for design purposes.

The results from this study can be directly used for structural design purposes. Furthermore, these results can also be used to develop a phase diagram for the studied alloy.

\section{ACKNOWLEDGEMENTS}

The authors acknowledge financial support and Fe-SMA material supply from re-fer AG. Furthermore, the laboratory staff of the Structural Engineering Research Laboratory and the Mechanical Engineering Systems Laboratory at Empa are acknowledged for their support in conducting the experimental investigation.

\section{REFERENCES}

1. Janke, L., C. Czaderski, M. Motavalli, and J. Ruth, Applications of shape memory alloys in civil engineering structures - Overview, limits and new ideas. Materials and Structures, 2005. 38(279): p. 578-592.

2. Cladera, A., B. Weber, C. Leinenbach, C. Czaderski, M. Shahverdi, and M. Motavalli, Iron-based shape memory alloys for civil engineering structures: An overview. Construction and Building Materials, 2014. 63: p. 281-293.

3. Mohd Jani, J., M. Leary, A. Subic, and M.A. Gibson, A review of shape memory alloy research, applications and opportunities. Materials \& Design, 2014. 56: p. 1078-1113.

4. Cladera, A., E. Oller, and C. Ribas, Pilot experiences in the application of shape memory alloys in structural concrete. Journal of Materials in Civil Engineering, 2014. 26(11).

5. Choi, E., D.J. Kim, Y.S. Chung, H.S. Kim, and C. Jung, Crack-closing of cement mortar beams using NiTi cold-drawn SMA short fibers. Smart Materials and Structures, 2015. 24(1).

6. Iwamoto, T. and B. Cao, A review on experimental investigations of rate sensitivity of deformation behavior in Fe-based shape memory alloys, in Advanced Structured Materials. 2017. p. 31-42.

7. Chang, W.S. and Y. Araki, Use of shape-memory alloys in construction: A critical review. Proceedings of the Institution of Civil Engineers: Civil Engineering, 2016. 169(2): p. 87-95.

8. Torra, V., A. Isalgue, F.C. Lovey, and M. Sade, Shape memory alloys as an effective tool to damp oscillations: Study of the fundamental parameters required to guarantee technological applications. Journal of Thermal Analysis and Calorimetry, 2015. 119(3): p. 1475-1533.

9. Choi, E., D.J. Kim, J.H. Hwang, and W.J. Kim, Prestressing effect of cold-drawn short NiTi SMA fibres in steel reinforced mortar beams. Smart Materials and Structures, 2016. 25(8).

10. Choi, E., T.H. Nam, Y.S. Chung, Y.W. Kim, and S.Y. Lee, Behavior of NiTiNb SMA wires under recovery stress or prestressing. Nanoscale Research Letters, 2012. 7: p. 111.

11. Wei, L. and Z. Xinqing, Mechanical Properties and Transformation Behavior of NiTiNb Shape Memory Alloys. Chinese Journal of Aeronautics, 2009. 22(5): p. 540-543. 
12. Dommer, K. and B. Andrawes, Thermomechanical characterization of NiTiNb shape memory alloy for concrete active confinement applications. Journal of Materials in Civil Engineering, 2012. 24(10): p. 1274-1282.

13. Indirli, M., M.G. Castellano, P. Clemente, and A. Martelli, Demo-application of Shape Memory Alloy devices: the rehabilitation of the S. Giorgio Church Bell-Tower, in SPIE Smart Structures and Materials 2001: Smart Systems for Bridges, Structures, and Highways, S.C. Liu, Editor. 2001. p. 262-272.

14. Castellano, M.G., M. Indirli, and A. Martelli, Progress of application, research and development and design guidelines for Shape Memory Alloy devices for cultural heritage structures in Italy, in Smart Structures and Materials 2001: Smart Systems for Bridges, Structures, and Highways, S.C. Liu, Editor. 2001. p. 250-261.

15. Moser, K., A. Bergamini, R. Christen, and C. Czaderski, Feasibility of concrete prestressed by shape memory alloy short fibers. Rilem, 2005.

16. Shin, M. and B. Andrawes, Experimental investigation of actively confined concrete using shape memory alloys. Engineering Structures, 2010. 32(3): p. 656-664.

17. Saiidi, M.S., M. Sadrossadat-Zadeh, C. Ayoub, and A. Itani, Pilot study of behavior of concrete beams reinforced with shape memory alloys. Journal of Materials in Civil Engineering, 2007. 19(6): p. 454-461.

18. Saiidi, M.S. and H.Y. Wang, Exploratory study of seismic response of concrete columns with shape memory alloys reinforcement. ACI Structural Journal, 2006. 103(3): p. 436443.

19. Mas, B., D. Biggs, I. Vieito, A. Cladera, J. Shaw, and F. Martínez-Abella, Superelastic shape memory alloy cables for reinforced concrete applications. Construction and Building Materials, 2017. 148: p. 307-320.

20. Ozbulut, O.E., S. Hurlebaus, and R. Desroches, Seismic response control using shape memory alloys: A review. Journal of Intelligent Material Systems and Structures, 2011. 22(14): p. 1531-1549.

21. Gencturk, B., Y. Araki, T. Kusama, T. Omori, R. Kainuma, and F. Medina, Loading rate and temperature dependency of superelastic $\mathrm{Cu}-\mathrm{Al}-\mathrm{Mn}$ alloys. Construction and Building Materials, 2014. 53: p. 555-560.

22. Araki, Y., T. Endo, T. Omori, Y. Sutou, Y. Koetaka, R. Kainuma, and K. Ishida, Potential of superelastic Cu-Al-Mn alloy bars for seismic applications. Earthquake Engineering and Structural Dynamics, 2011. 40(1): p. 107-115.

23. Leinenbach, C., H. Kramer, C. Bernhard, and D. Eifler, Thermo-mechanical properties of an $\mathrm{Fe}-\mathrm{Mn}$-Si-Cr-Ni-VC shape memory alloy with low transformation temperature. Advanced Engineering Materials, 2012. 14(1-2): p. 62-67.

24. Sato, A., E. Chishima, K. Soma, and T. Mori, Shape memory effect in $\gamma \rightleftarrows \varepsilon$ transformation in Fe-30Mn-1Si alloy single crystals. Acta Metallurgica, 1982. 30(6): p. 1177-1183.

25. Sawaguchi, T., I. Nikulin, K. Ogawa, K. Sekido, S. Takamori, T. Maruyama, Y. Chiba, A. Kushibe, Y. Inoue, and K. Tsuzaki, Designing Fe-Mn-Si alloys with improved lowcycle fatigue lives. Scripta Materialia, 2015. 99: p. 49-52.

26. Nikulin, I., T. Sawaguchi, K. Ogawa, and K. Tsuzaki, Effect of $\gamma$ to $\varepsilon$ martensitic transformation on low-cycle fatigue behaviour and fatigue microstructure of Fe-15Mn10Cr-8Ni-xSi austenitic alloys. Acta Materialia, 2016. 105: p. 207-218.

27. Sawaguchi, T., T. Maruyama, H. Otsuka, A. Kushibe, Y. Inoue, and K. Tsuzaki, Design concept and applications of $\mathrm{Fe}$-Mn-Si-based alloys-from shape-memory to seismic response control. Materials Transactions, 2016. 57(3): p. 283-293.

28. Watanabe, Y., E. Miyazaki, and H. Okada, Enhanced Mechanical Properties of Fe-MnSi-Cr Shape Memory Fiber/Plaster Smart Composite. MATERIALS TRANSACTIONS, 2002. 43(5): p. 974-983.

29. Soroushian, P., K. Ostowari, A. Nossoni, and H. Chowdhury, Repair and strengthening of concrete structures through application of corrective posttensioning forces with shape memory alloys, in Transportation Research Record. 2001. p. 20-26. 
30. Dong, Z., U.E. Klotz, C. Leinenbach, A. Bergamini, C. Czaderski, and M. Motavalli, $A$ novel $\mathrm{Fe}-\mathrm{Mn}$-Si shape memory alloy with improved shape recovery properties by $V C$ precipitation. Advanced Engineering Materials, 2009. 11(1-2): p. 40-44.

31. Lee, W.J., B. Weber, G. Feltrin, C. Czaderski, M. Motavalli, and C. Leinenbach, Phase transformation behavior under uniaxial deformation of an $\mathrm{Fe}-\mathrm{Mn}-\mathrm{Si}-\mathrm{Cr}-\mathrm{Ni}-\mathrm{VC}$ shape memory alloy. Materials Science and Engineering: A, 2013. 581(0): p. 1-7.

32. Lee, W.J., B. Weber, G. Feltrin, C. Czaderski, M. Motavalli, and C. Leinenbach, Stress recovery behaviour of an $\mathrm{Fe}-\mathrm{Mn}-\mathrm{Si}-\mathrm{Cr}-\mathrm{Ni}-\mathrm{VC}$ shape memory alloy used for prestressing. Smart Materials and Structures, 2013. 22(12): p. 9.

33. Czaderski, C., B. Weber, M. Shahverdi, M. Motavalli, C. Leinenbach, W. Lee, R. Brönnimann, and J. Michels. Iron-based shape memory alloys (Fe-SMA) a new material for prestressing concrete structures. in SMAR 2015, Antalya, Turkey, 7-9 September 2015, Keynote lecture. 2015.

34. Czaderski, C., B. Hahnebach, and M. Motavalli, RC beam with variable stiffness and strength. Construction and Building Materials, 2006. 20(9): p. 824-833.

35. Moser, K., A. Bergamini, R. Christen, and C. Czaderski, Feasibility of concrete prestressed by shape memory alloy short fibers. Materials and Structures, 2005. 38(279): p. 593-600.

36. Czaderski, C., M. Shahverdi, R. Brönnimann, C. Leinenbach, and M. Motavalli, Feasibility of iron-based shape memory alloy strips for prestressed strengthening of concrete structures. Construction and Building Materials, 2014. 56: p. 94-105.

37. Shahverdi, M., C. Czaderski, and M. Motavalli, Iron-based shape memory alloys for prestressed near-surface mounted strengthening of reinforced concrete beams. Construction and Building Materials, 2016. 112: p. 28-38.

38. Shahverdi, M., C. Czaderski, P. Annen, and M. Motavalli, Strengthening of RC beams by iron-based shape memory alloy bars embedded in a shotcrete layer. Engineering Structures, 2016. 117: p. 263-273.

39. Maruyama, T. and H. Kubo, 12 - Ferrous (Fe-based) shape memory alloys (SMAs): properties, processing and applications, in Shape Memory and Superelastic Alloys, K. Yamauchi, et al., Editors. 2011, Woodhead Publishing. p. 141-159.

40. Baruj, A., G. Bertolino, and H.E. Troiani, Temperature dependence of critical stress and pseudoelasticity in a $\mathrm{Fe}-\mathrm{Mn}-\mathrm{Si}-\mathrm{Cr}$ pre-rolled alloy. Journal of Alloys and Compounds, 2010. 502(1): p. 54-58.

41. Michels, J., M. Shahverdi, C. Czaderski, B. Schranz, and M. Motavalli, Iron based shape memory alloy strips, part 2: flexural strengthening of RC beams SMAR2017, 2017.

42. Michels, J., M. Shahverdi, and C. Czaderski, Flexural strengthening of structural concrete with iron-based shape memory alloy strips. Structural Concrete, 2017.

43. Ebschner, P. and G.P. Terrasi, test report Nr. 5214009925, test results of the Fe-SMA specimens. 2016: Empa. p. 18.

44. DecentlabGmbH. Available from: https://www.decentlab.com/\#customers. 
546 Table 1. List of Fe-SMA strips under tensile loading, studied using testing set-up No. 1

\begin{tabular}{|c|c|c|c|c|c|c|c|}
\hline $\begin{array}{l}\text { Strip } \\
\text { No. }\end{array}$ & $\begin{array}{l}\text { Cut out - M (mid- } \\
\text { dle) or R (border) }\end{array}$ & $\begin{array}{c}\text { Thickness, } \\
t \\
{[\mathrm{~mm}]}\end{array}$ & $\begin{array}{c}\text { Width, } \\
b \\
{[\mathrm{~mm}]}\end{array}$ & $\begin{array}{c}\text { Offset yield } \\
\text { point, } R_{\mathrm{p} 0.2} \\
\text { [MPa] }\end{array}$ & $\begin{array}{c}\text { Maximum } \\
\text { Stress, } f_{\mathrm{u}} \\
{[\mathrm{MPa}]}\end{array}$ & $\begin{array}{c}\text { Strain } \\
\text { at } f_{\mathrm{u}} \\
{[\%]}\end{array}$ & $\begin{array}{c}\text { Maximum } \\
\text { strain, } \varepsilon_{\max } \\
{[\%]}\end{array}$ \\
\hline S-1 & M & 0.5 & 15 & 496.93 & 1000.75 & 51.50 & 53.47 \\
\hline S-2 & $\mathrm{M}$ & 0.5 & 15 & 500.83 & 967.02 & 47.22 & 48.22 \\
\hline S-3 & M & 0.5 & 15 & 502.13 & 963.38 & 45.27 & 47.90 \\
\hline S-4 & $\mathrm{R}$ & 1.5 & 15 & 537.70 & 976.39 & 38.12 & 42.42 \\
\hline S-5 & $\mathrm{R}$ & 1.5 & 15 & 538.12 & 976.25 & 38.46 & 41.62 \\
\hline S-6 & $\mathrm{R}$ & 1.5 & 15 & 532.63 & 975.98 & 36.81 & 41.74 \\
\hline S-7 & $\mathrm{R}$ & 1.5 & 15 & 537.77 & 984.74 & 40.61 & 44.66 \\
\hline S-8 & $\mathrm{R}$ & 1.5 & 15 & 527.64 & 982.97 & 39.55 & 43.55 \\
\hline S-9 & M & 1.5 & 15 & 533.63 & 991.63 & 39.63 & 43.53 \\
\hline
\end{tabular}

547

548 Table 2. List of Fe-SMA strips subjected to recovery strain measurement in testing set-up No. 2

\begin{tabular}{cccccccc}
\hline $\begin{array}{c}\text { Strip } \\
\text { No. }\end{array}$ & $\begin{array}{c}\text { Cut out - } \\
\text { M (mid- } \\
\text { dle) or R } \\
\text { (border) }\end{array}$ & $\begin{array}{c}\text { Thickness, } \\
t \\
{[\mathrm{~mm}]}\end{array}$ & $\begin{array}{c}\text { Width, } \\
b \\
{[\mathrm{~mm}]}\end{array}$ & $\begin{array}{c}\text { Prestrain, } \\
\mathcal{E}_{\mathrm{p}} \\
{[\%]}\end{array}$ & $\begin{array}{c}\text { Pre- } \\
\text { load, } \\
P_{\text {ini }} \\
{[\mathrm{MPa}]}\end{array}$ & $\begin{array}{c}\text { Maximum tem- } \\
\text { perature, } T_{\max } \\
{\left[{ }^{\circ} \mathrm{C}\right]}\end{array}$ & $\begin{array}{c}\text { Recovery strain, } \\
\varepsilon_{\text {rec }} \\
{[\%]}\end{array}$ \\
\hline S-10 & $\mathrm{R}$ & 1.5 & 10 & 0.5 & 1 & 160 & 0.16 \\
S-11 & $\mathrm{R}$ & 1.5 & 10 & 1 & 1 & 160 & 0.25 \\
S-12 & $\mathrm{M}$ & 1.5 & 10 & 2 & 1 & 160 & 0.37 \\
S-13 & $\mathrm{R}$ & 1.5 & 10 & 2 & 1 & 160 & 0.37 \\
S-14 & $\mathrm{R}$ & 1.5 & 10 & 2 & 1 & 160 & 0.36 \\
S-15 & $\mathrm{M}$ & 1.5 & 10 & 4 & 1 & 160 & 0.32 \\
S-16 & $\mathrm{R}$ & 1.5 & 10 & 4 & 1 & 160 & 0.33 \\
S-17 & $\mathrm{R}$ & 1.5 & 10 & 4 & 1 & 160 & 0.38 \\
S-18 & $\mathrm{R}$ & 1.5 & 10 & 4 & 1 & 160 & 0.38 \\
S-19 & $\mathrm{R}$ & 1.5 & 10 & 4 & 1 & 160 & 0.39 \\
S-20 & $\mathrm{R}$ & 1.5 & 10 & 6 & 1 & 160 & 0.36 \\
\hline
\end{tabular}


Table 3. List of Fe-SMA strips activated in the climate-controlled chamber in testing set-up No. 2

\begin{tabular}{|c|c|c|c|c|c|c|c|}
\hline StripNo. & $\begin{array}{l}\text { Cut out -M } \\
\text { (middle) or } \\
\mathrm{R} \text { (border) }\end{array}$ & $\begin{array}{c}\text { Thickness, } \\
t \\
{[\mathrm{~mm}]}\end{array}$ & $\begin{array}{l}\text { Width, } \\
b[\mathrm{~mm}]\end{array}$ & $\begin{array}{c}\text { Prestrain, } \varepsilon_{\mathrm{p}} \\
{[\%]}\end{array}$ & $\begin{array}{c}\text { Machine } \\
\text { preload, } \\
P_{\text {ini }} \\
{[\mathrm{MPa}]}\end{array}$ & $\begin{array}{c}\text { Maximum } \\
\text { temperature, } \\
T_{\max } \\
{\left[{ }^{\circ} \mathrm{C}\right]}\end{array}$ & $\begin{array}{c}\text { Recovery } \\
\text { stress, } \sigma_{\text {rec }} \\
{[\mathrm{MPa}]}\end{array}$ \\
\hline S-21 & $\mathrm{R}$ & 1.5 & 15 & 0.5 & 50 & 160 & 259.59 \\
\hline S-22 & M & 1.5 & 15 & 0.5 & 50 & 160 & 291.79 \\
\hline S-23 & M & 1.5 & 15 & 0.5 & 50 & 160 & 293.07 \\
\hline S-24 & $\mathrm{R}$ & 1.5 & 15 & 1 & 50 & 160 & 291.57 \\
\hline S-25 & $\mathrm{R}$ & 1.5 & 15 & 1 & 50 & 160 & 326.57 \\
\hline S-26 & $\mathrm{R}$ & 1.5 & 15 & 1 & 50 & 160 & 327.72 \\
\hline S-27 & M & 1.5 & 15 & 2 & 50 & 120 & 270.77 \\
\hline S-28 & M & 1.5 & 15 & 2 & 50 & 120 & 273.30 \\
\hline S-29 & $\mathrm{R}$ & 1.5 & 15 & 2 & 50 & 140 & 274.32 \\
\hline S-30 & $\mathrm{R}$ & 1.5 & 15 & 2 & 50 & 140 & 276.20 \\
\hline S-31 & $\mathrm{R}$ & 1.5 & 15 & 2 & 50 & 120 & 277.69 \\
\hline S-32 & $\mathrm{R}$ & 1.5 & 15 & 2 & 50 & 160 & 303.32 \\
\hline S-33 & $\mathrm{R}$ & 1.5 & 15 & 2 & 50 & 160 & 310.52 \\
\hline S-34 & M & 0.5 & 15 & 2 & 50 & 160 & 317.55 \\
\hline S-35 & $\mathrm{R}$ & 1.5 & 15 & 2 & 50 & 160 & 328.00 \\
\hline S-36 & M & 1.5 & 15 & 2 & 50 & 160 & 342.46 \\
\hline S-37 & $\mathrm{R}$ & 1.5 & 15 & 2 & 50 & 160 & 344.66 \\
\hline S-38 & M & 1.5 & 15 & 2 & 50 & 160 & 346.10 \\
\hline S-39 & M & 1.5 & 15 & 2 & 50 & 160 & 348.84 \\
\hline S-40 & M & 1.5 & 15 & 2 & 50 & 195 & 379.69 \\
\hline S-41 & M & 1.5 & 15 & 2 & 50 & 195 & 387.69 \\
\hline S-42 & M & 1.5 & 15 & 2 & 50 & 195 & 392.77 \\
\hline S-43 & M & 0.5 & 15 & 4 & 50 & 160 & 315.63 \\
\hline S-44 & $\mathrm{R}$ & 1.5 & 15 & 4 & 50 & 160 & 322.00 \\
\hline S-45 & $\mathrm{R}$ & 1.5 & 15 & 4 & 70 & 160 & 324.00 \\
\hline S-46 & $\mathrm{R}$ & 1.5 & 15 & 4 & 50 & 160 & 324.00 \\
\hline S-47 & M & 1.5 & 15 & 4 & 50 & 160 & 329.17 \\
\hline S-48 & $\mathrm{R}$ & 1.5 & 15 & 4 & 70 & 160 & 330.00 \\
\hline S-49 & M & 0.5 & 15 & 4 & 50 & 160 & 331.02 \\
\hline S-50 & M & 1.5 & 15 & 4 & 50 & 160 & 334.00 \\
\hline S-51 & $\mathrm{M}$ & 1.5 & 15 & 4 & 50 & 160 & 338.79 \\
\hline
\end{tabular}


552 Table 4. List of Fe-SMA strips activated in the air in testing set-up No. 4

\begin{tabular}{ccccccc}
\hline $\begin{array}{c}\text { Strip } \\
\text { No. }\end{array}$ & $\begin{array}{c}\text { Thickness, } t \\
{[\mathrm{~mm}]}\end{array}$ & $\begin{array}{c}\text { Width, } b \\
{[\mathrm{~mm}]}\end{array}$ & $\begin{array}{c}\text { Prestrain, } \varepsilon_{\mathrm{p}} \\
{[\%]}\end{array}$ & $\begin{array}{c}\text { Pre-load, } \\
P_{\text {ini }} \\
{[\mathrm{MPa}]}\end{array}$ & $\begin{array}{c}\text { Maximum } \\
\text { temperature, } \\
T_{\max } \\
{\left[{ }^{\circ} \mathrm{C}\right]}\end{array}$ & $\begin{array}{c}\text { Recovery stress, } \\
\sigma_{\text {rec }} \\
{[\mathrm{MPa}]}\end{array}$ \\
\hline L-1 & 1.5 & 10 & 2 & 10 & 190 & 389 \\
L-2 & 1.5 & 10 & 2 & 10 & 268 & 443 \\
L-3 & 1.5 & 10 & 2 & 10 & 280 & 395 \\
L-4 & 1.5 & 10 & 2 & 10 & 177 & 356 \\
L-5 & 1.5 & 10 & 2 & 10 & 171 & 334 \\
L-6 & 1.5 & 10 & 2 & 10 & 380 & 445 \\
\hline
\end{tabular}

553

554 Table 5. List of Fe-SMA strips subjected to long-term loading (relaxation) in testing set-up No. 4

\begin{tabular}{|c|c|c|c|c|c|c|c|c|c|c|}
\hline $\begin{array}{l}\text { Strip } \\
\text { No. }\end{array}$ & $\begin{array}{l}\text { Thick- } \\
\text { ness, } t \\
{[\mathrm{~mm}]}\end{array}$ & $\begin{array}{l}\text { Wid } \\
\text { th, } b \\
{[\mathrm{~mm}} \\
\quad]\end{array}$ & $\begin{array}{c}\text { Pre- } \\
\text { strain, } \\
\varepsilon_{p} \\
{[\%]}\end{array}$ & $\begin{array}{l}\text { Experi- } \\
\text { ment } \\
\text { type, see } \\
\text { Section } \\
3.4 .3\end{array}$ & $\begin{array}{c}\text { Pre- } \\
\text { load, } \\
P_{\text {ini }} \\
{[\mathrm{MPa}]}\end{array}$ & $\begin{array}{c}\text { Maxi- } \\
\text { mum } \\
\text { temperat } \\
\text { pera- } \\
\text { ture, } \\
T_{\max } \\
{\left[{ }^{\circ} \mathrm{C}\right]} \\
\end{array}$ & $\begin{array}{l}\text { Recov- } \\
\text { ery } \\
\text { stress, } \\
\sigma_{r e c} \\
{[\mathrm{MPa}]}\end{array}$ & $\begin{array}{c}\text { Load af- } \\
\text { ter acti- } \\
\text { vation, } \\
P_{\text {ser }} \\
{[\mathrm{MPa}]}\end{array}$ & $\begin{array}{c}\text { Time } \\
\text { under } \\
\text { load- } \\
\text { ing, } \\
\mathrm{t}_{\text {relx }} \\
{[\mathrm{h}]}\end{array}$ & $\begin{array}{c}\text { Relaxation, } \\
\Delta \sigma_{\text {relx }} / \sigma_{\max } \\
{[\%]}\end{array}$ \\
\hline L-7 & 1.5 & 10 & 2 & $i$ & 330 & - & - & - & 1423 & 9.0 \\
\hline L-8 & 1.5 & 10 & 2 & $i i$ & 10 & 160 & 378 & - & 712 & 9.3 \\
\hline L-9 & 1.5 & 10 & 2 & $i i$ & 10 & 160 & 380 & - & 1674 & 9.9 \\
\hline L-10 & 1.5 & 10 & 2 & $i i i$ & 10 & 160 & 375 & 85 & 960 & 8.9 \\
\hline L-11 & 1.5 & 10 & 2 & $i i i$ & 10 & 160 & 390 & 95 & 1960 & 9.7 \\
\hline
\end{tabular}




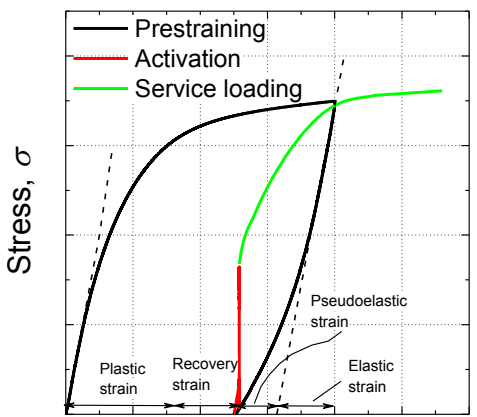

Strain, $\varepsilon$

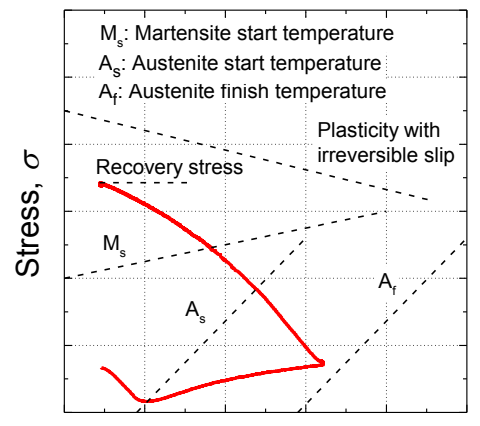

Temperature, $T$

558 Figure 1. Left: schematic of three main actions in SMA application for prestressing a RC member. Right: schematic illustration of the activation ( $2^{\text {nd }}$ action) and the recovery stress development
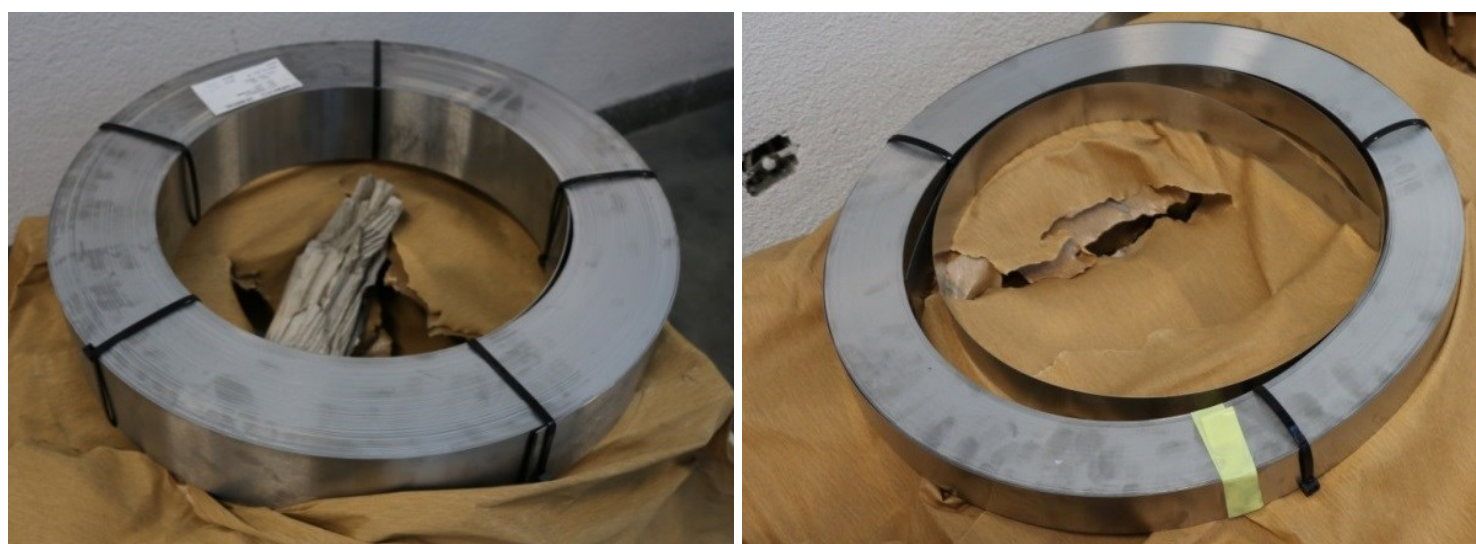

Figure 2. Fe-SMA strips. Left: $1.5 \mathrm{~mm}$ thickness and $100 \mathrm{~mm}$ width, Right: $0.5 \mathrm{~mm}$ thickness and $50 \mathrm{~mm}$ width
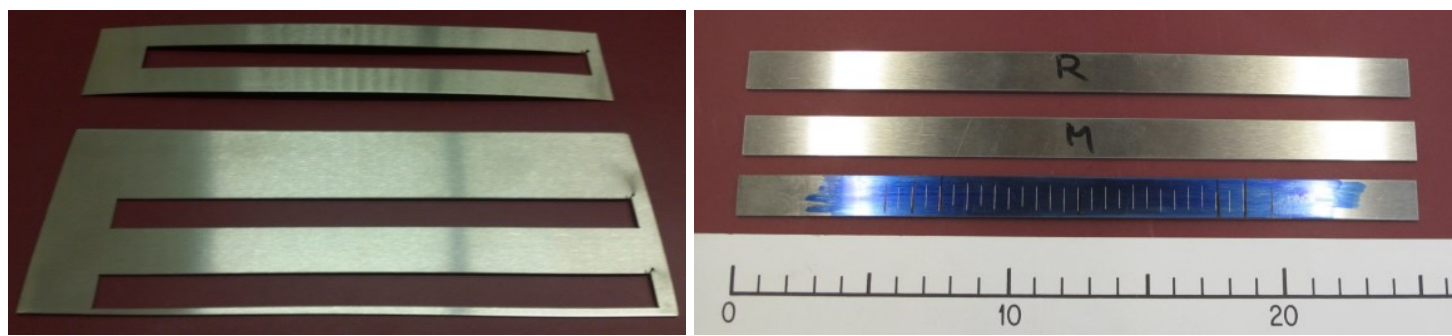

Figure 3. Left - cut out from the Fe-SMA strips; on top: Fe-SMA strips with $0.5 \mathrm{~mm}$ thickness and on bottom: Fe-SMA strips with $1.5 \mathrm{~mm}$ thickness cut out from the middle and the border. Right: Fe-SMA strips before the tensile test; marks on the painted background are for strain measurements. The scale dimensions are in $\mathrm{cm}$ 


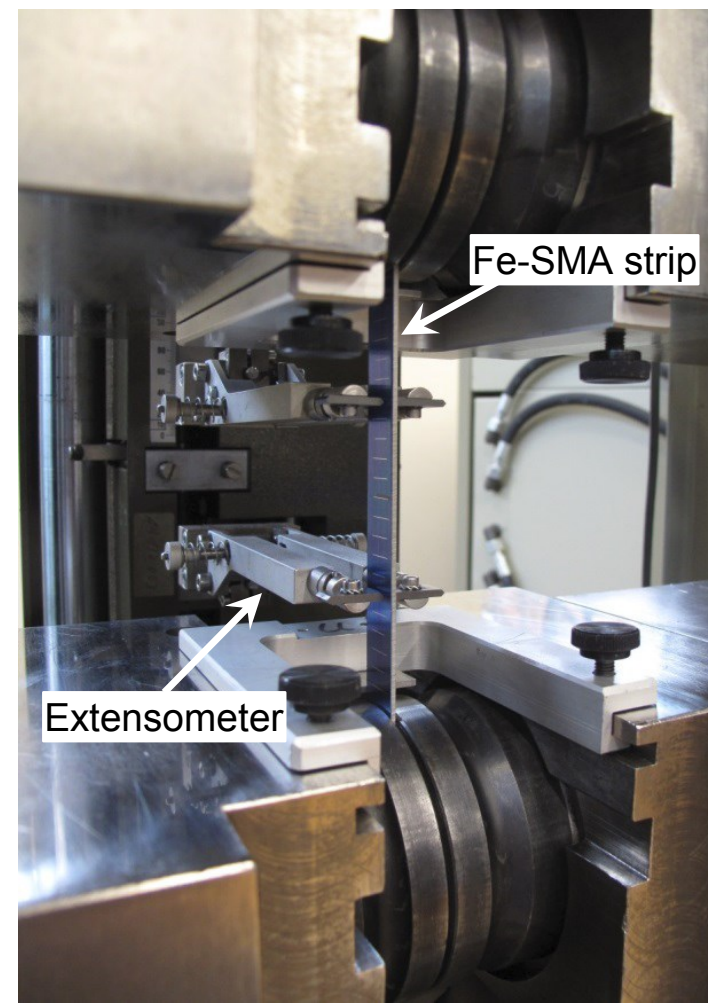

Figure 4. Fe-SMA strips installed in a Zwick testing machine equipped with an extensometer over a length of $100 \mathrm{~mm}$ [43] (testing set-up No. 1)

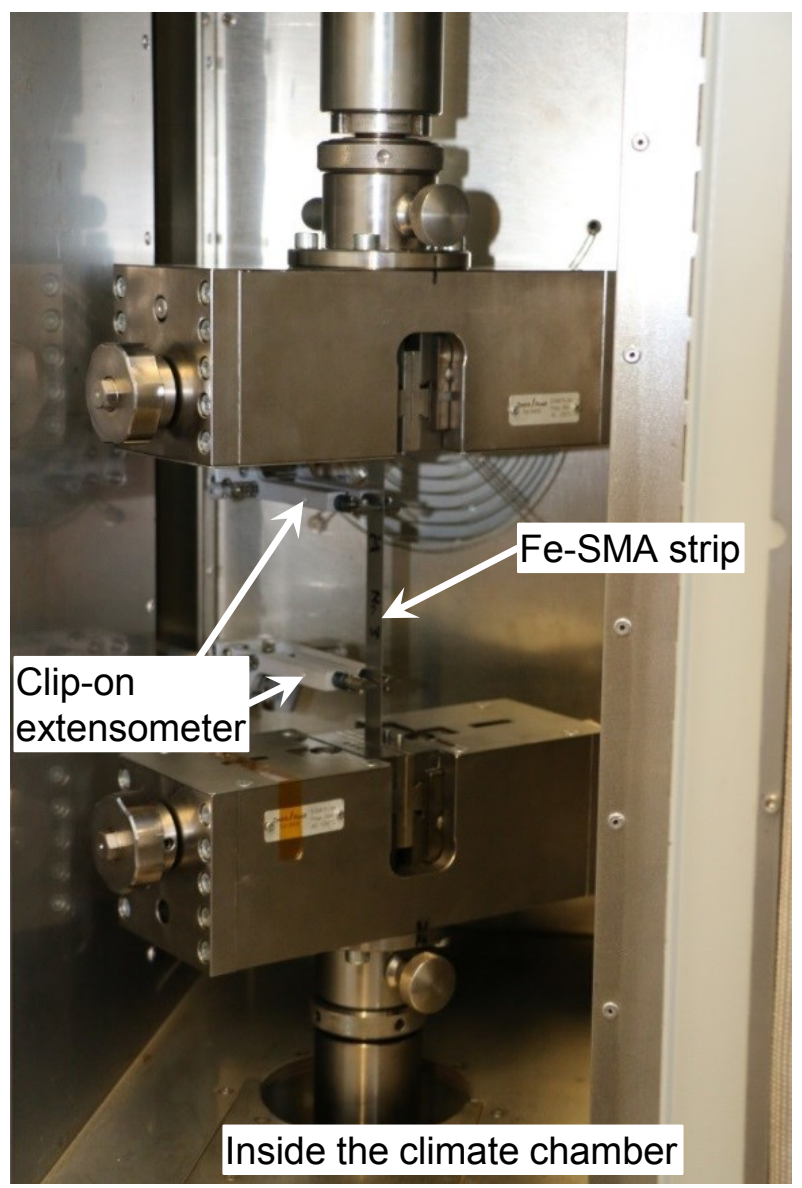

Figure 5. A $20 \mathrm{kN}$ Zwick machine equipped with a climate-controlled chamber. The machine was used for prestraining and activation of the Fe-SMA test specimens (testing set-up No. 2) 

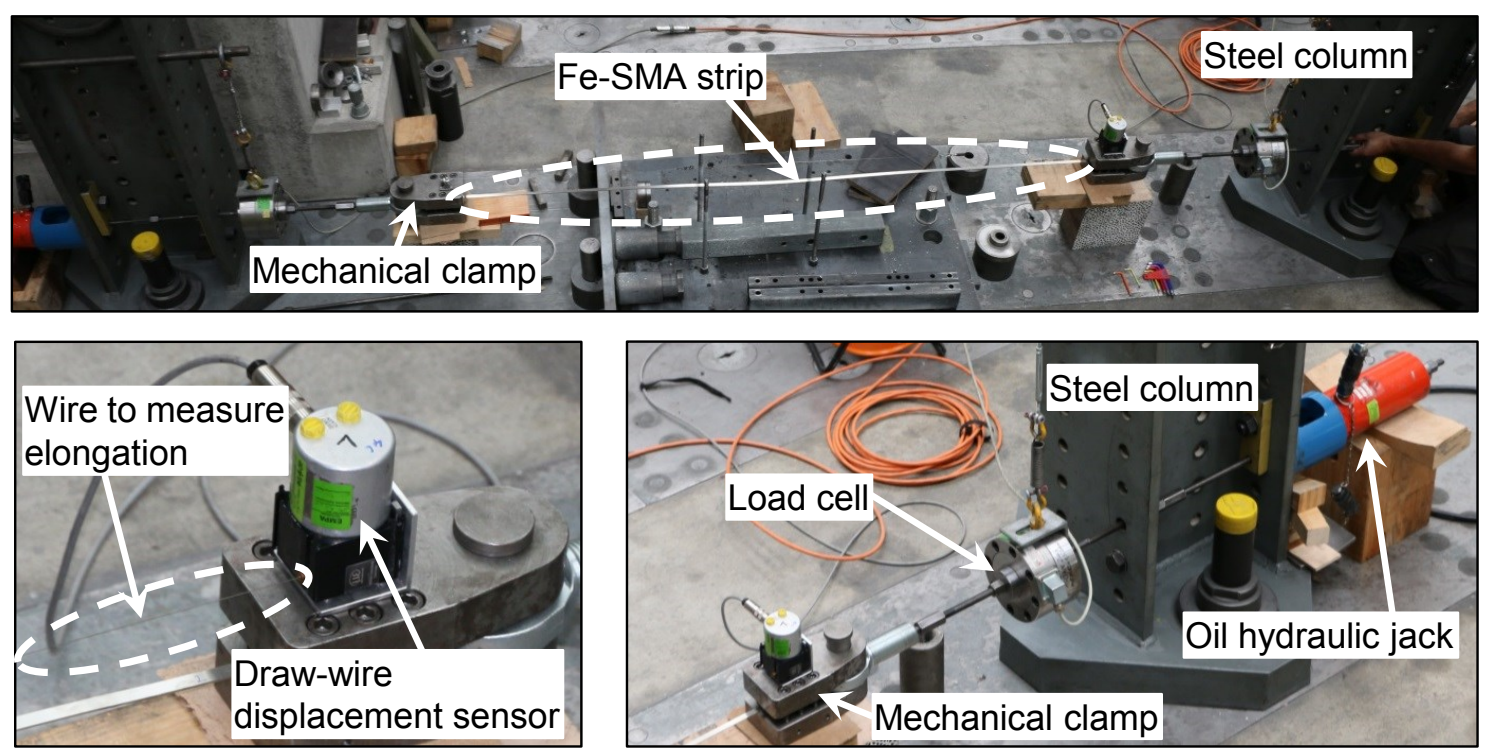

576 Figure 6. Set-up and instrumentation for the prestraining of long Fe-SMA strips (testing set-up No. 3)
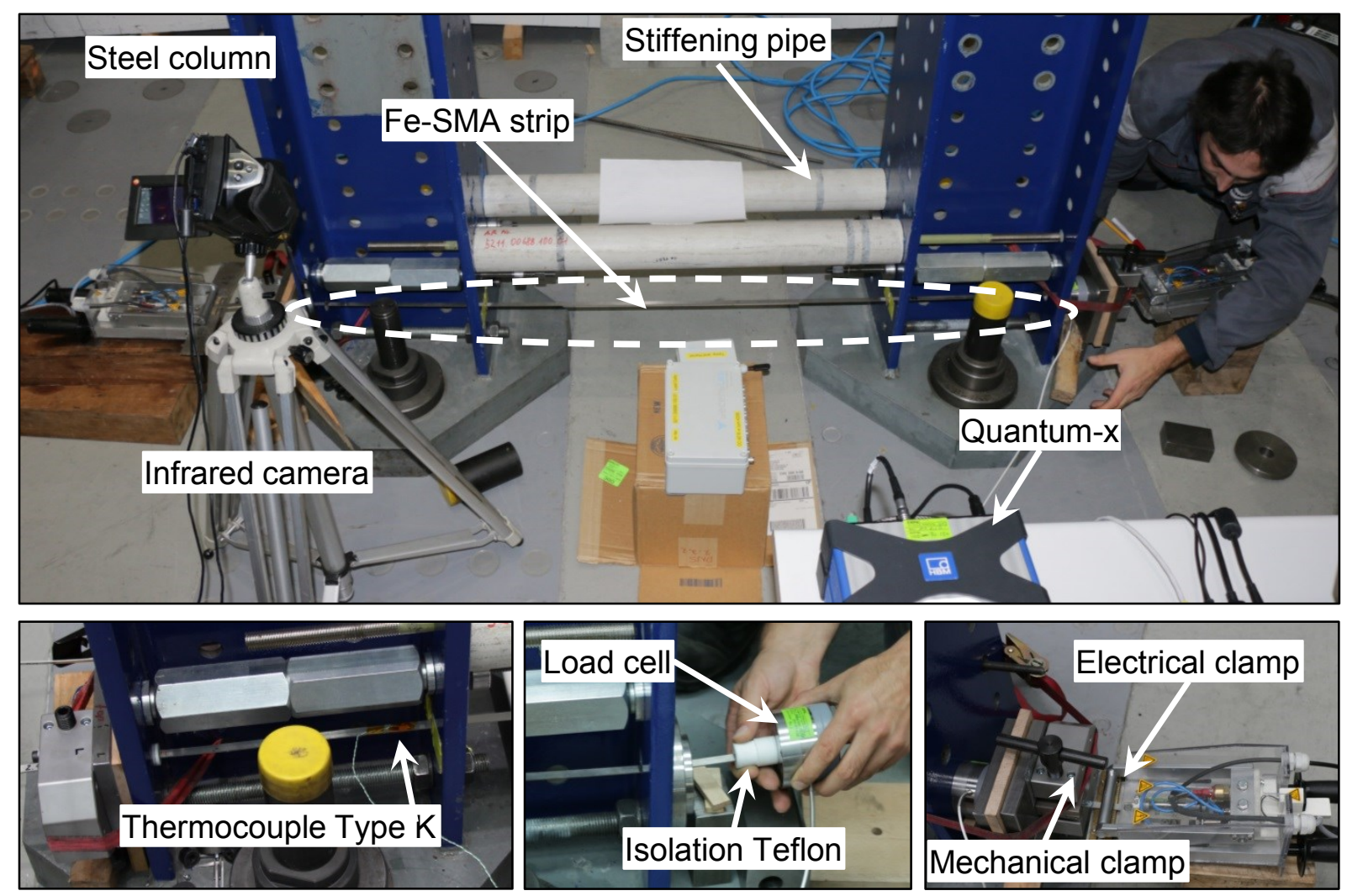

578 Figure 7. Set-up and instrumentation for the activation of long Fe-SMA strips in air (testing set-up No. 4) 


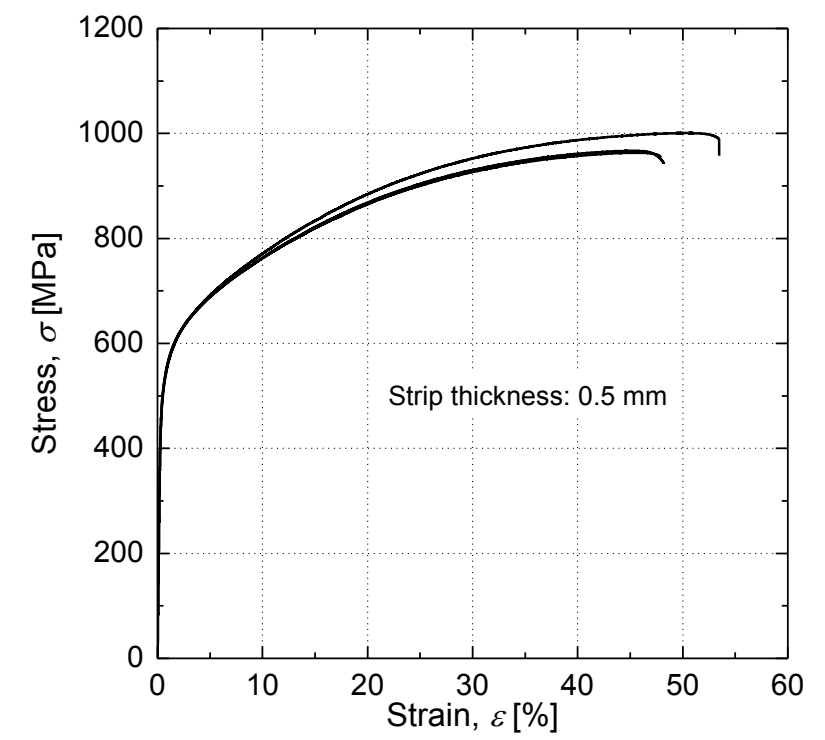

Figure 8. Stress-strain diagrams of 0.5-mm-thick Fe-SMA strips from tensile experiments performed in 581 testing set-up No. 1

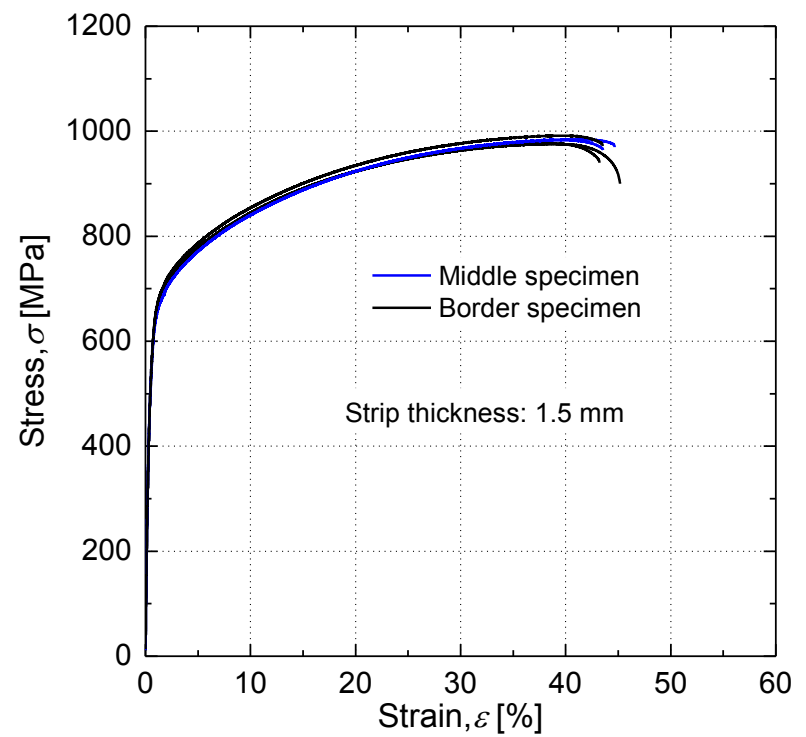

Figure 9. Stress-strain diagrams of 1.5-mm-thick Fe-SMA strips from tensile experiments performed in testing set-up No. 1 


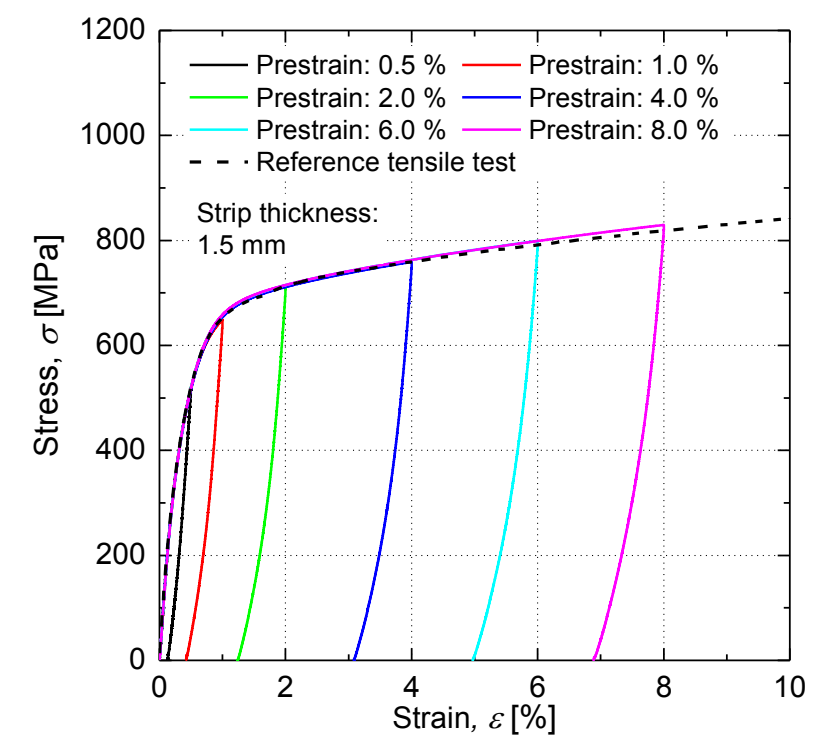

Figure 10. Stress-strain diagrams from prestraining experiments on 1.5-mm-thick short Fe-SMA strips 587 (testing set-up No. 2)

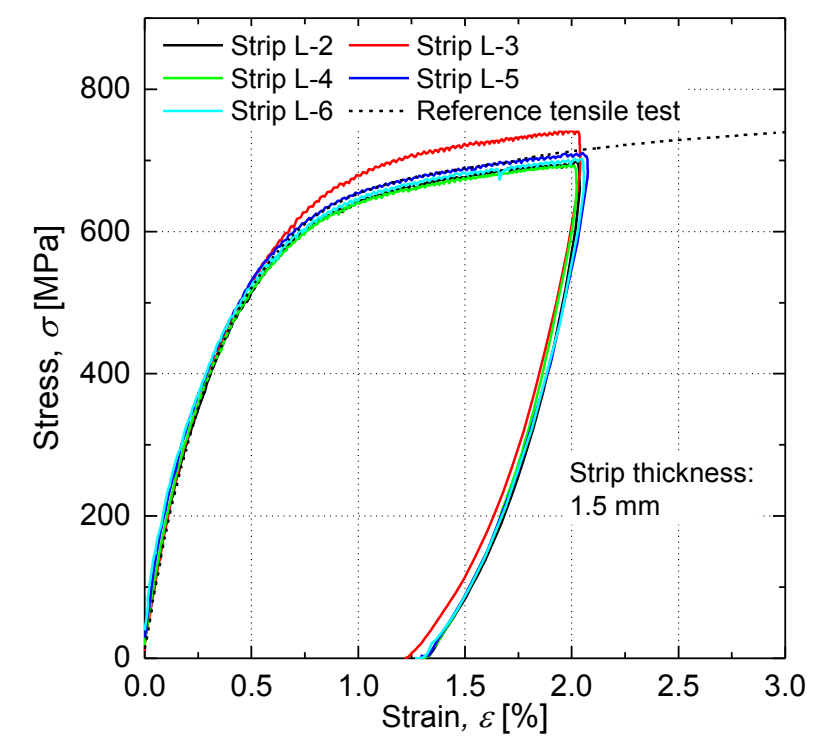

Figure 11. Stress-strain diagrams from prestraining experiments on 1.5-mm-thick long Fe-SMA strips 590 (testing set-up No. 3) 


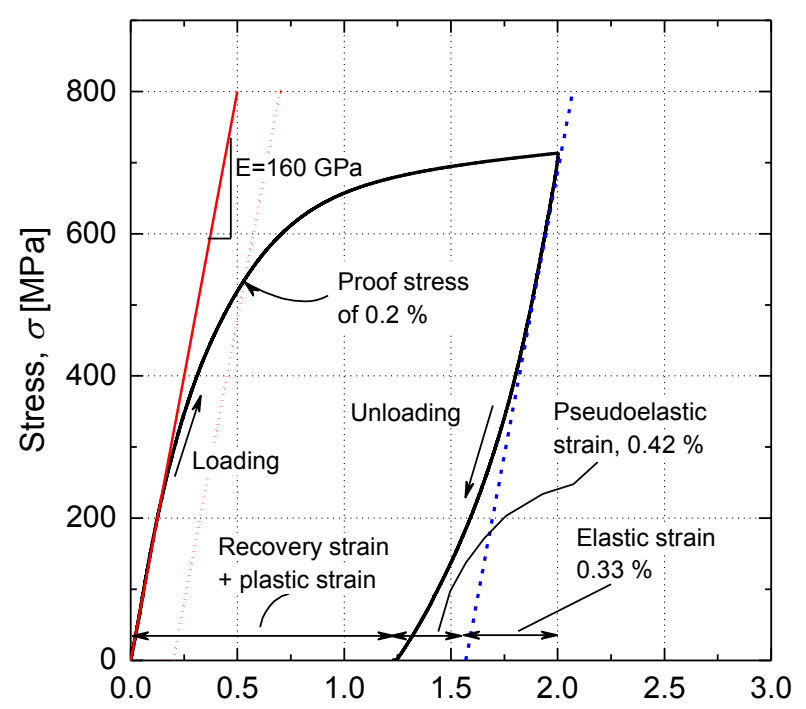

591

Strain, $\varepsilon[\%]$

592 Figure 12. Prestraining (2.0\%) diagram of a 1.5-mm-thick Fe-SMA strip (testing set-up No. 2)

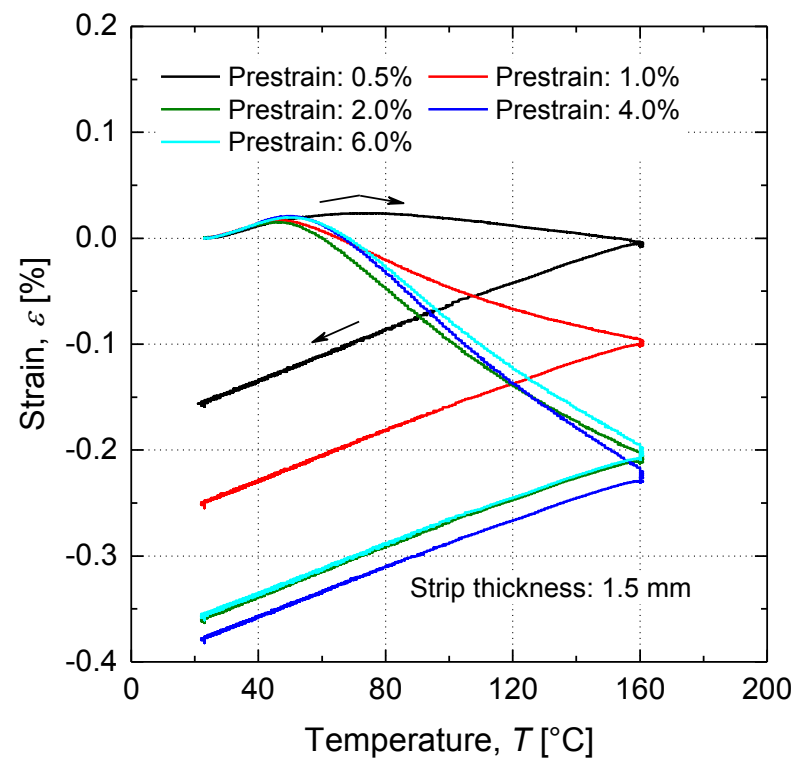

593

Figure 13. Recovery strain measurement performed in testing set-up No. 2 


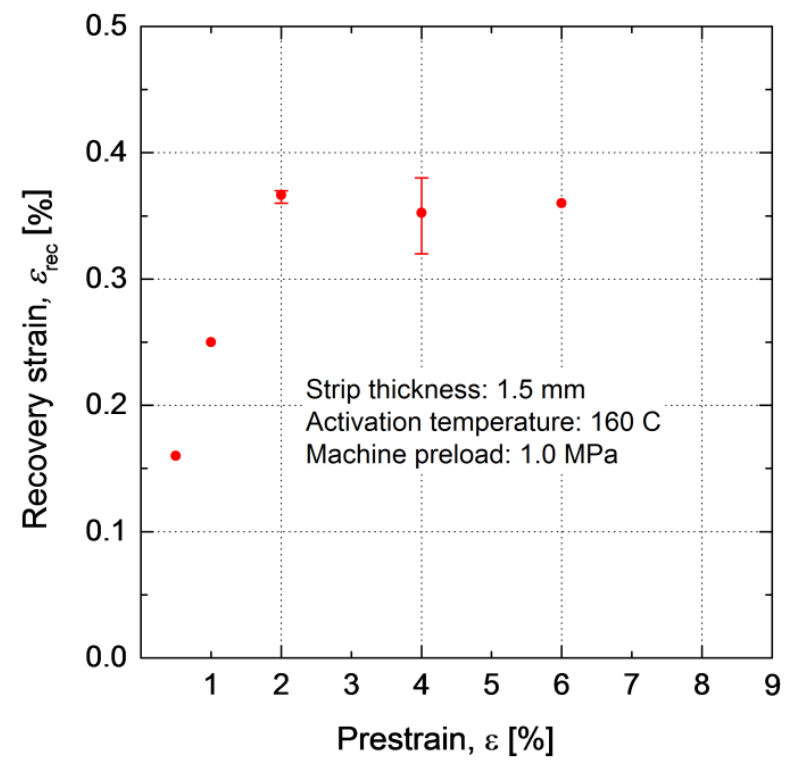

595

598

Figure 14. Effect of strip prestraining on the recovery strain for the 1.5-mm-thick Fe-SMA strips subjected to a maximum temperature of $160^{\circ} \mathrm{C}$ (testing set-up No. 2)

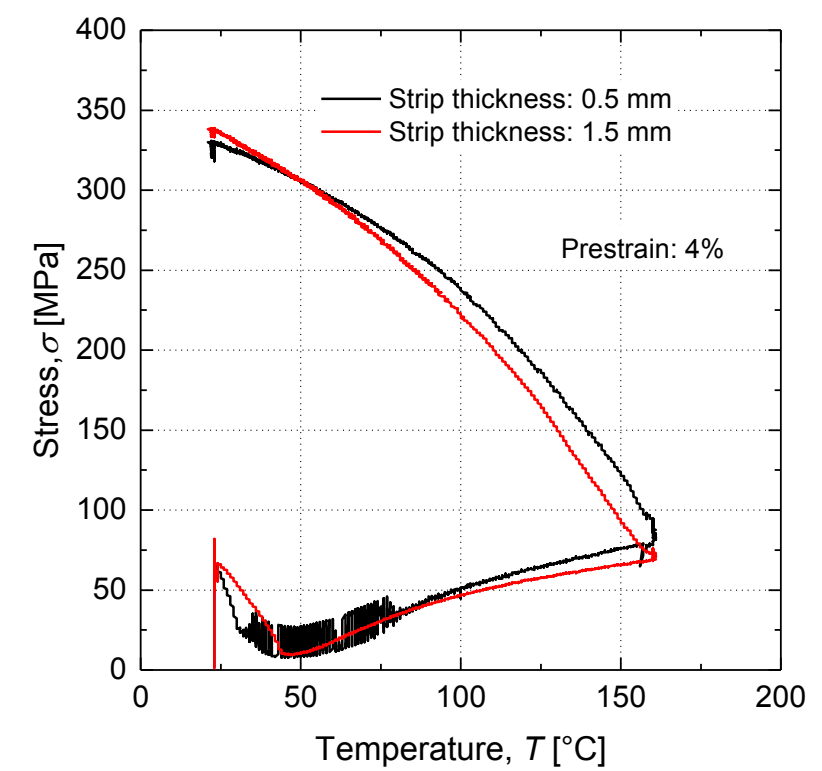

Figure 15. Effect of strip thickness on the recovery stress versus temperature curves of the Fe-SMA strips subjected to $4.0 \%$ prestrain (testing set-up No. 2) 


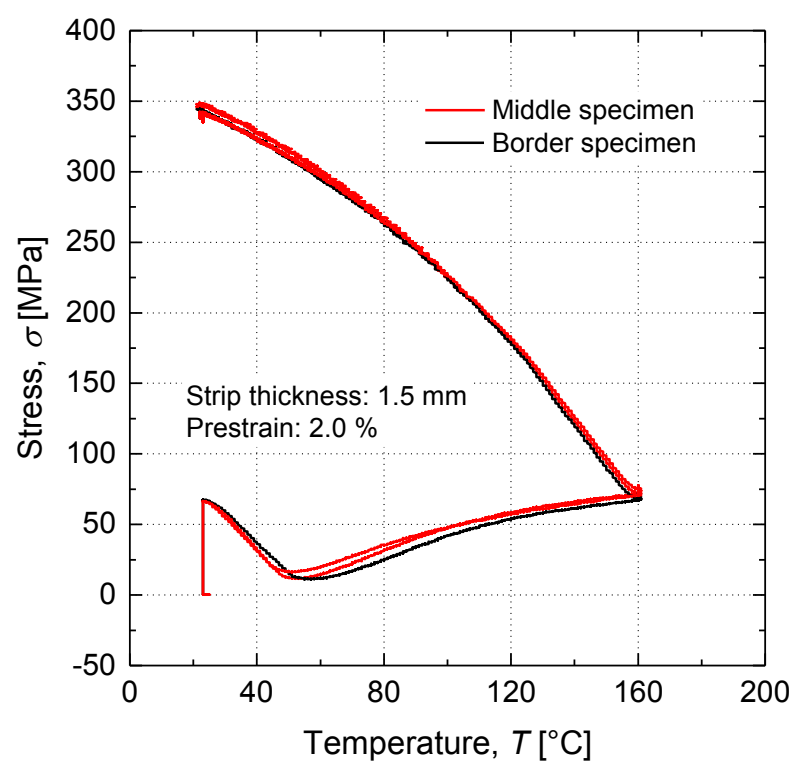

Figure 16. Effect of strip position cut on the recovery stress versus temperature curves of the $1.5-\mathrm{mm}-$ thick Fe-SMA strips subjected to a $2.0 \%$ prestrain (testing set-up No. 2)

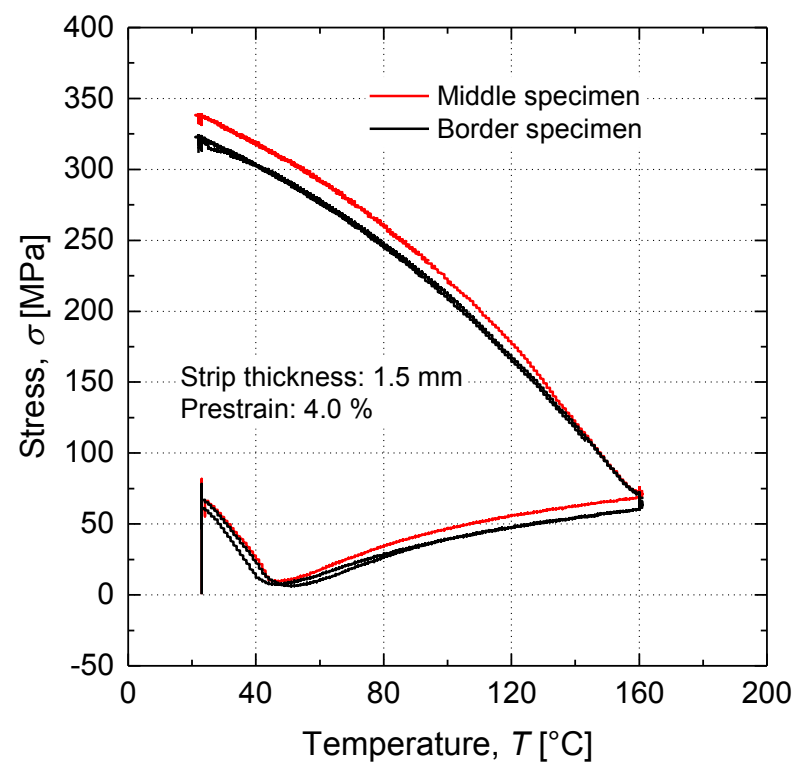

Temperature, $T\left[{ }^{\circ} \mathrm{C}\right]$

606 Figure 17. Effect of strip position cut on the recovery stress versus temperature curves of the 1.5-mm607 thick Fe-SMA strips subjected to $4.0 \%$ prestrain (testing set-up No. 2) 


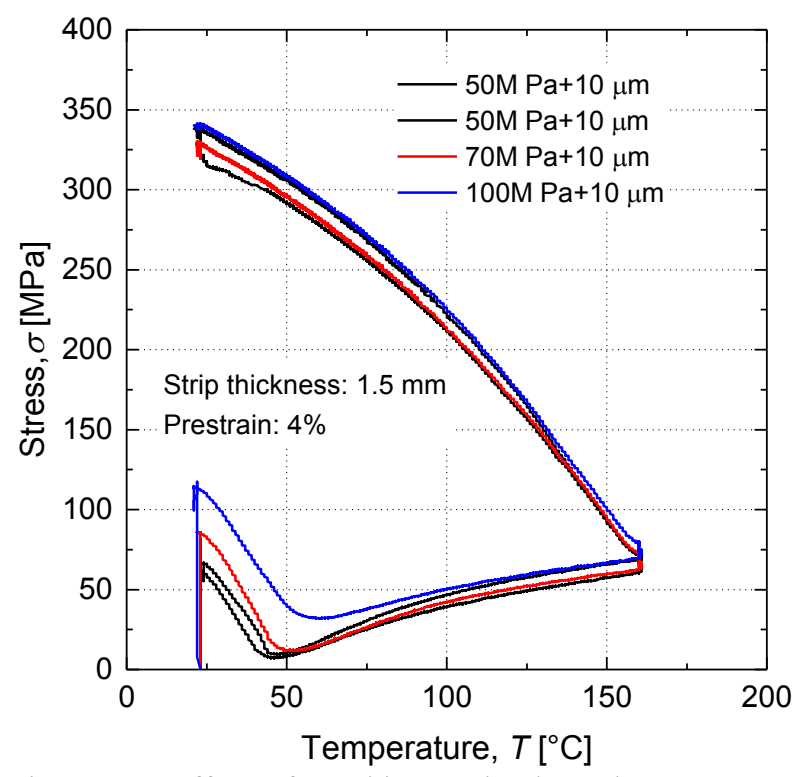

Figure 18. Effect of machine preload on the recovery stress versus temperature curves of the $1.5-\mathrm{mm}-$ thick Fe-SMA strips subjected to $4.0 \%$ prestrain (testing set-up No. 2)

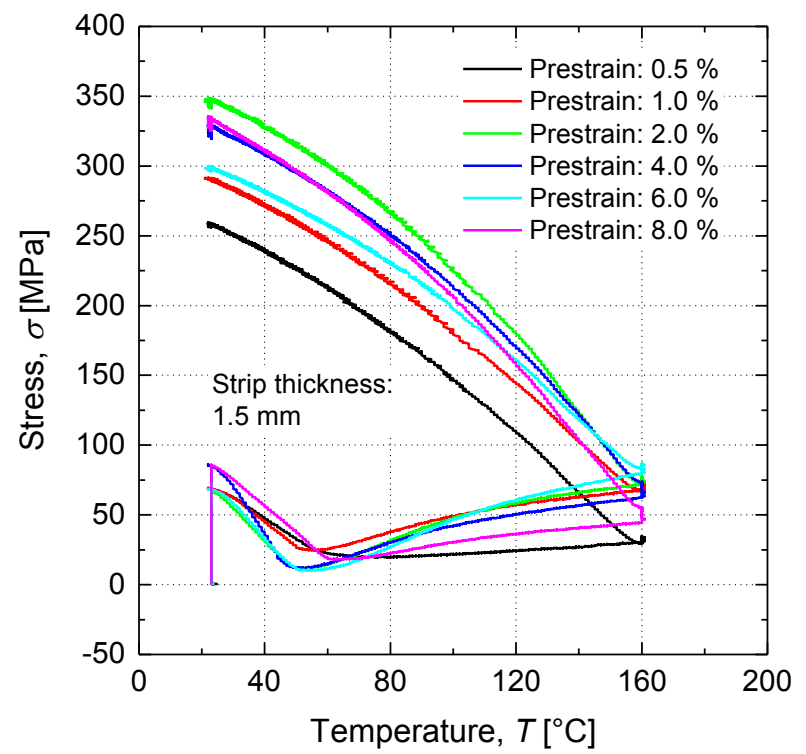

Figure 19. Recovery stress versus temperature curves of the 1.5-mm-thick Fe-SMA strips at different prestrain levels subjected to a maximum temperature of $160^{\circ} \mathrm{C}$ (testing set-up No. 2) 


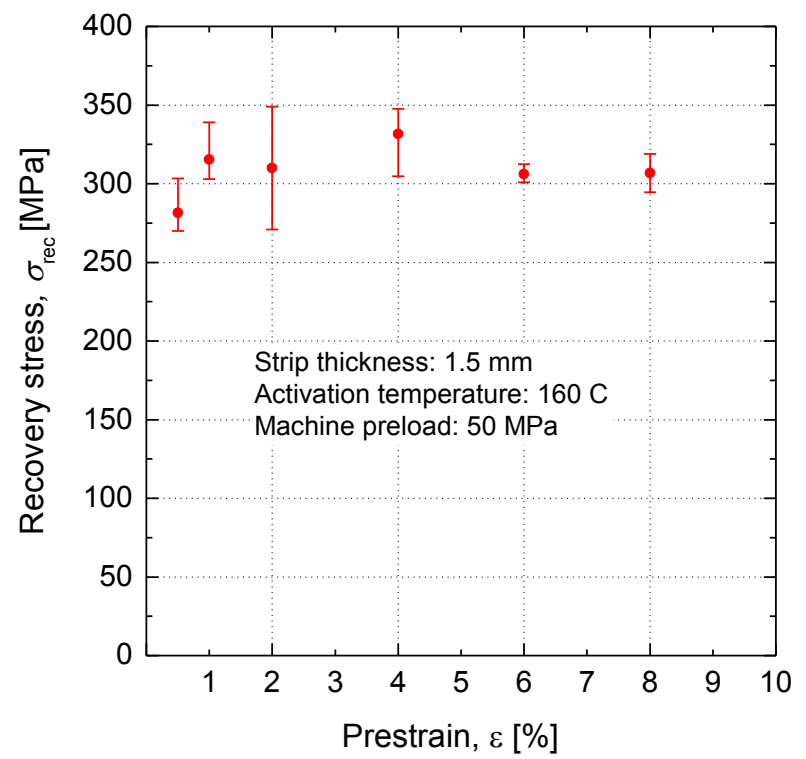

614

615

Figure 20. Effect of strip prestraining on the recovery stress for the 1.5-mm-thick Fe-SMA strips subject616 ed to a maximum temperature of $160^{\circ} \mathrm{C}$ (testing set-up No. 2)

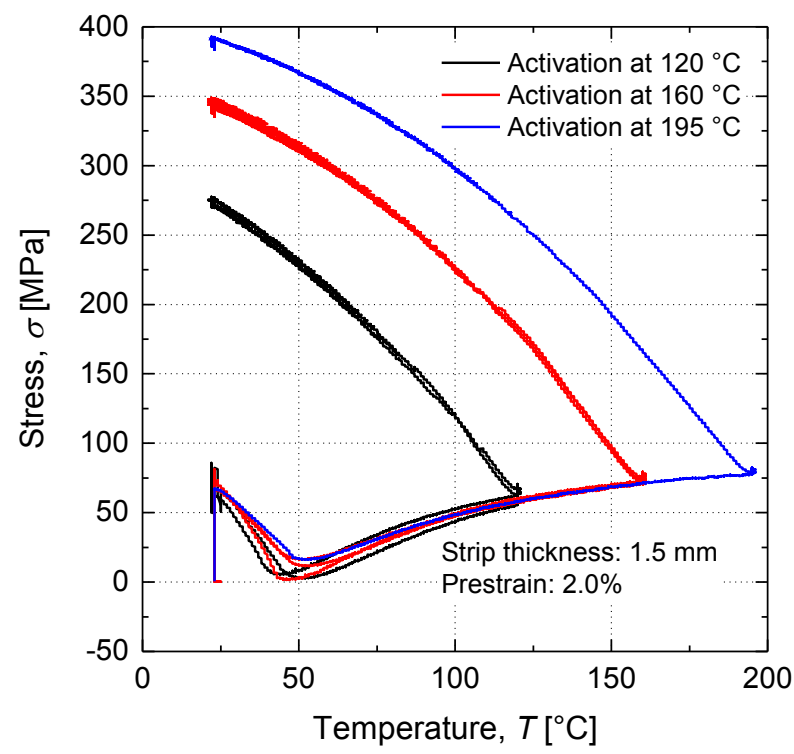

618 Figure 21. Recovery stress versus temperature curves of the 1.5-mm-thick Fe-SMA strips subjected to $6192.0 \%$ prestrain in the climate chamber (testing set-up No. 2)
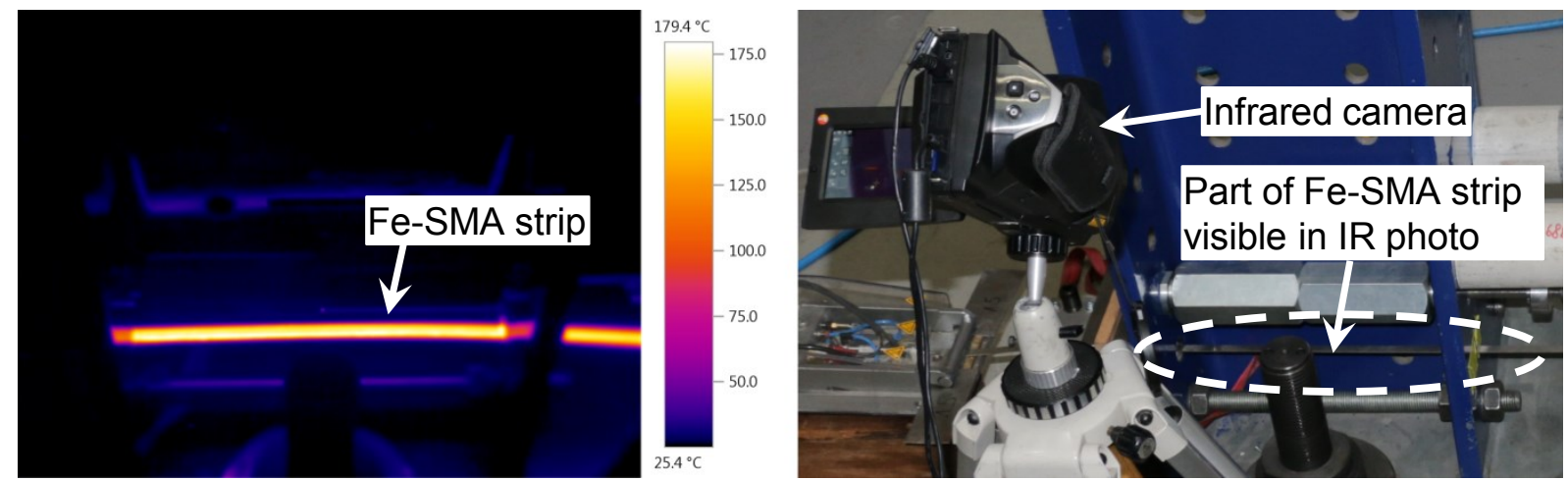

Figure 22. Left: A photo captured by the infrared camera during the activation of a Fe-SMA strip in air.

Right: Actual photo of the Fe-SMA strip visible in the infrared photo (testing set-up No. 4) 


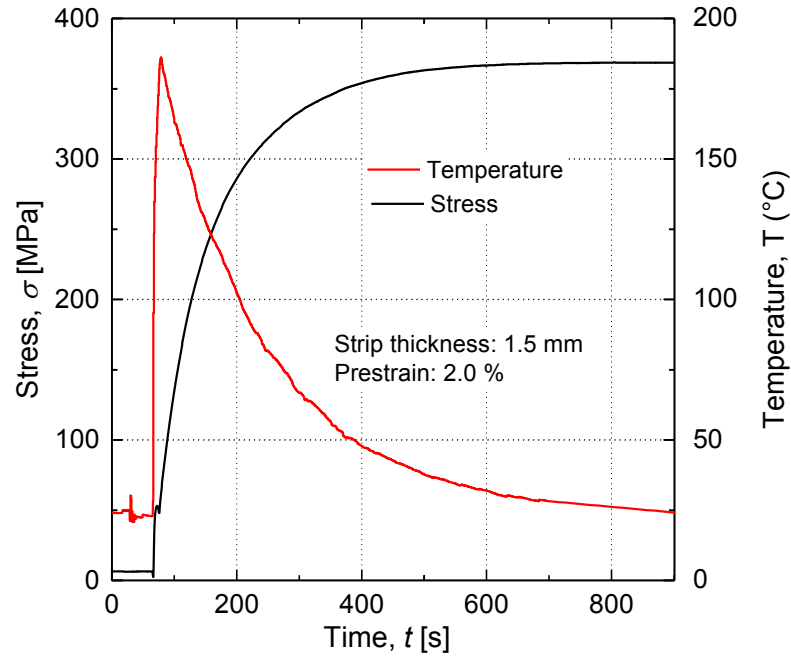

Figure 23. Stress and temperature measurement in a long Fe-SMA strip activated in air (testing set-up No. 4)

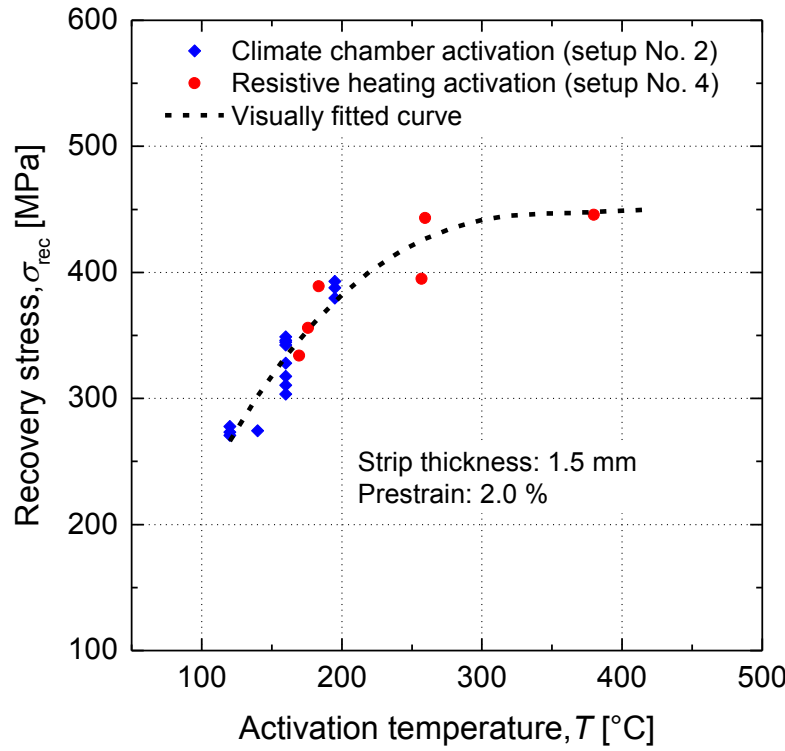

Figure 24. Effect of maximum temperature on the recovery stress versus temperature curves of the 1.5mm-thick Fe-SMA strips subjected to $2.0 \%$ prestrain (testing set-up No. 2 and 4 ) 


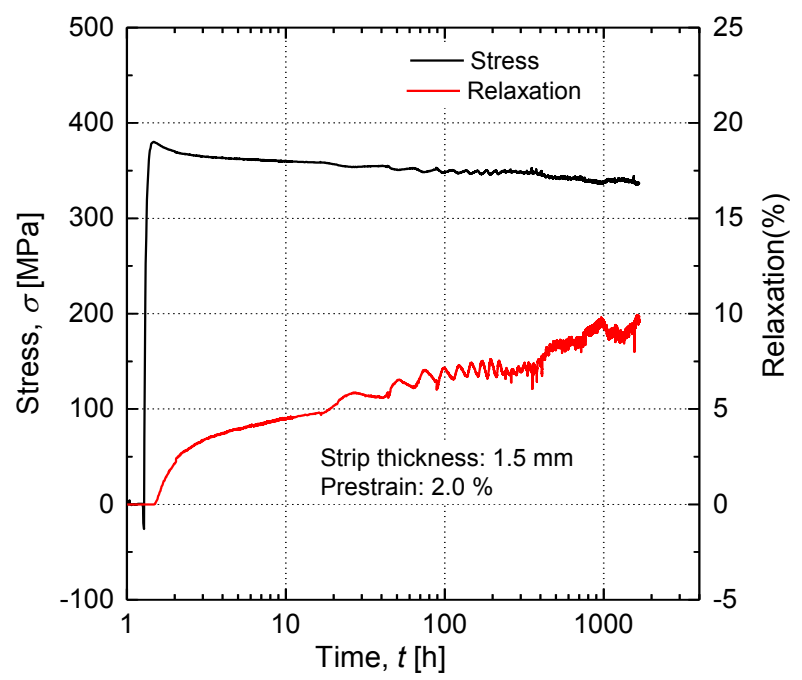

Figure 25. Stress relaxation of a Fe-SMA strip activated in air to a recovery stress of about $380 \mathrm{MPa}$ (testing set-up No. 4)

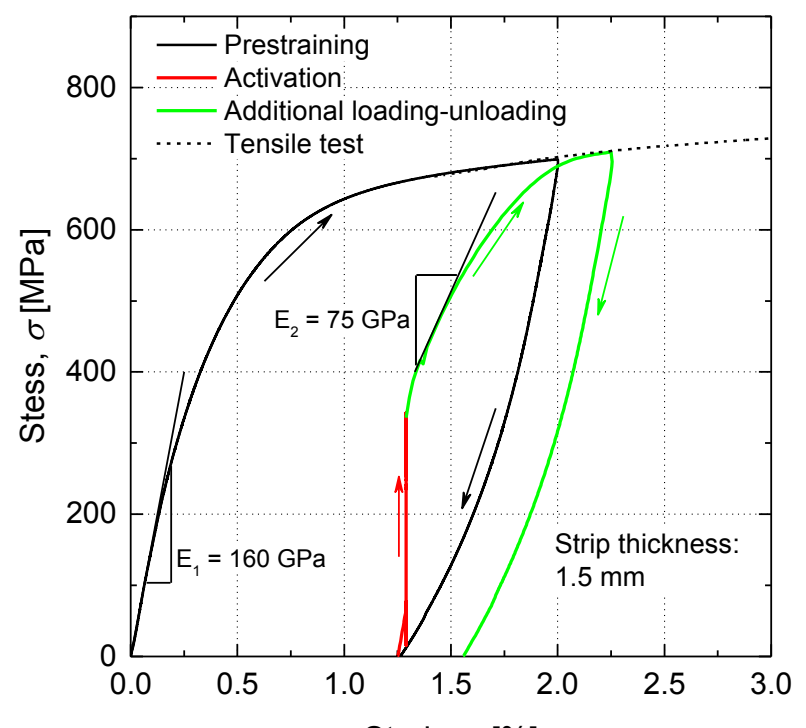

Strain, $\varepsilon[\%]$

635 Figure 26. Stress-strain behavior of a 1.5-mm-thick Fe-SMA strip prestrained to 2.0\%, activated at a max636 imum temperature of $160{ }^{\circ} \mathrm{C}$, and subjected to an additional tensile load which is 3-4 times greater than 637 the service load (testing set-up No. 2) 


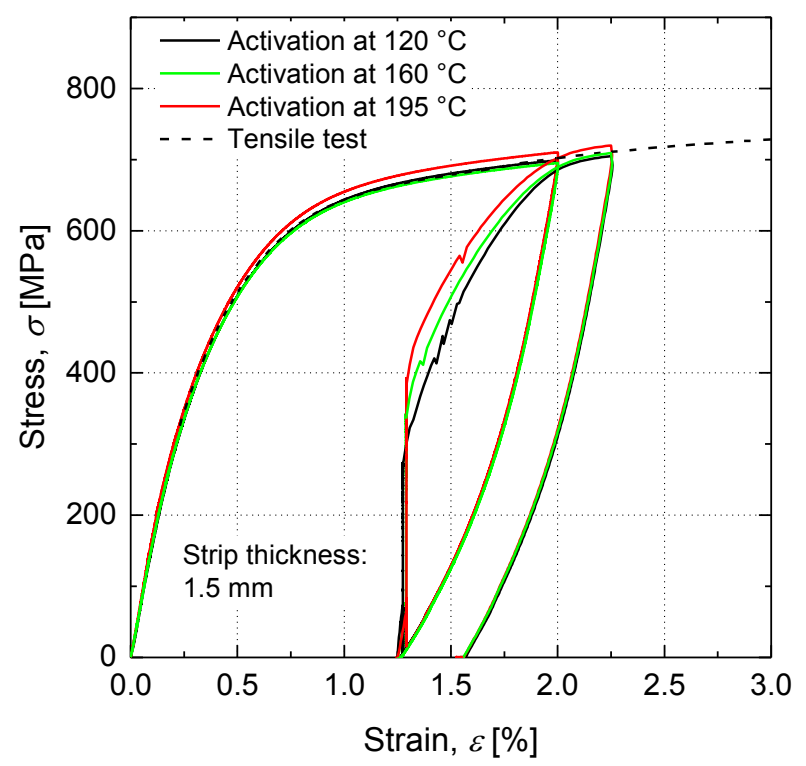

Figure 27. Stress-strain behavior of a 1.5-mm-thick Fe-SMA strip prestrained to $2.0 \%$, activated at differload (testing set-up No. 2) 